\title{
SERVICIOS DE INTELIGENCIA, SECRETO Y GARANTÍA JUDICIAL DE LOS DERECHOS
}

\author{
JUAN FRANCISCO SÁNCHEZ BARRILAO \\ Profesor Titular de Derecho Constitucional \\ Universidad de Granada
}

SUMARIO

I. Introducción. Más allá del caso Villarejo: sociedad del riesgo y seguridad integral. II. Servicios de inteligencia: CNI y comunidad de inteligencia. III. Inteligencia, secreto y Estado de Derecho. IV. Inteligencia, control jurisdiccional y tutela judicial efectiva. V. Inteligencia y control judicial previo. VI. Sobre la necesaria reforma del control jurídico sobre la inteligencia.

\section{INTRODUCCIÓN. MÁS ALLÁ DEL CASO VILLAREJO: SOCIEDAD DEL RIESGO Y SEGURIDAD INTEGRAL ${ }^{1}$}

La investigación judicial de las actividades presuntamente delictivas del excomisario Villarejo que se desarrolla en estos días además de sacar a la luz múltiples actividades de todo tipo (tanto de información, como de extorsión; de carácter público, como privadas; políticas, como económicas; etc.) contrarias a Derecho (con el evidente escándalo, mas sin llegar a plantearse, entendemos, la exigencia de responsabilidades públicas en el grado que debieran darse al margen de las penales), vuelve a traer a la palestra constitucional las dificultades del control judicial sobre ámbitos propios de la inteligencia, la seguridad y el secreto; y es que a cada paso de dicha instrucción se arriba, de una u otra forma, a espacios donde la labor de los servicios de inteligencia, la seguridad nacional y el secreto de Estado afloran. Esto, por sí, justifica retornar al debate del control sobre la actividad de inteligencia, y en especial al respecto de información sensible para la seguridad nacional; mas ello, también, a la vista de

1 Este trabajo se ha realizado en el marco del Proyecto «Los derechos fundamentales ante las crisis económicas y de seguridad en un marco constitucional fragmentado» (DER2016-77924-P). 
cómo hoy progresa el riesgo, y a su sombra la propia seguridad y la inteligencia. Así, entonces, que propongamos analizar el marco constitucional desde el que articular la garantía judicial de los derechos a la sombra de la acción de los servicios de inteligencia y en especial con relación a materias consideradas secretas; y a tales efectos, que primero hagamos una preliminar aproximación a qué entendamos por servicios de inteligencia (en España), luego presentemos el régimen jurídico del secreto hoy, para finalmente profundizar en su debido control judicial en garantía de derechos. Pero antes, y conforme se ha adelantado, permítasenos contextualizar la labor de inteligencia y su control jurisdiccional a tenor de un riesgo in crecesdo y una búsqueda de mayor seguridad a su rebufo.

Comenzando por el riesgo, desde la segunda mitad del siglo pasado la sociedad viene caracterizándose por éste: es decir, por la progresiva potencialidad para generar gravísimos daños; y ello al hilo del progreso tecnológico y la globalización, pues mientras la tecnología aporta los recursos que generan dicho riesgo, la globalización lo amplía en sus orígenes y efectos ${ }^{2}$. Los atentados en Nueva York en 2001 habrían puesto así en evidencia cómo una tecnología civil, la aviación comercial, se instrumentalizaba como arma en un atentado de masas ${ }^{3}$, mientras era retransmitido a nivel global por televisión ${ }^{4}$; y bajo su espectro, que tomara cuerpo una nueva sociedad hasta ese momento meramente teorizada (al respecto de las contradicciones y paradojas que la tecnología y la globalización comportaban ya), a la par que se precipitaba en un acentuado y paulatino proceso de desorientación e incertidumbre 5 .

Tan complejo contexto ha dado lugar a una nueva concepción de la seguridad, en cuanto que más allá de la seguridad pública y de la defensa, además de compuesta, integral y preventiva (L 36/2015, de 28 de septiembre, de Seguridad Nacional; y al hilo de ésta, STC 184/2016, de 3 de noviembre de 2016, en especial FJ núm. 3). Y al servicio de la misma, un necesario impulso de la inteligencia $^{6}$ no sólo al respecto de las formas de obtener y tratar la información, sino sobre la propia información y los objetivos a alcanzar, como de su ulterior evaluación y

2 U. BECK, La sociedad del riesgo (Hacia una nueva modernidad), J. Navarro et al. (trad.), Paidós, Barcelona, 1998 .

3 Desde esta perspectiva, B. ACKerman, «The Emergency Constitution», The Yale Law Journal, vol. $113, \mathrm{n}^{\circ}$ 5, 2004, p. 1029.

4 Vid. D. Sansó-Rubert Pascual, «Nuevos tiempos, viejas amenazas», Estrategia global: revista de relaciones internacionales, economía, defensa y tecnología, $\mathrm{n}^{\circ} 13,2006$, pp. 66 y ss.

5 Z. Bauman: Tiempos líquidos (Vivir en una época de incertidumbre), $5^{\mathrm{a}}$ ed., C. Corral (trad.), Tusquets Editores, Barcelona, 2015; y La globalización (Consecuencias humanas), $2^{\mathrm{a}}$ ed. (1ª reimp.), D. Zadunaisky (trad.), Fondo de Cultura Económica, Madrid, 2017.

6 Cfr. V. Díaz Blanco, «Finalidad de la inteligencia», AA.VV. Inteligencia. Un enfoque integral, Ministerio de Defensa / Instituto Español de Estudios Estratégicos, Madrid, 2016, p. 48. En cuanto a la L 36/2015, ésta considera la inteligencia como apoyo «permanentemente al Sistema de Seguridad Nacional» con el que proporcionar «elementos de juicio, información, análisis, estudios y propuestas necesarios para prevenir y detectar los riesgos y amenazas y contribuir a su neutralización» (art. 9.2). 
examen $^{7}$. La inteligencia, en tanto que información evaluada, se entiende como instrumento esencial ante la toma de decisiones, además de, y especialmente, como medio para advertir riesgos y amenazas, y de esta forma prevenir resultados gravemente lesivos para el interés general ${ }^{8}$.

Mas lo anterior, sin perder de vista que la inteligencia, dado que actividad pública (sin perjuicio de que sea desarrollada por sujetos privados en colaboración con aquélla $)^{9}$, se inserta en una sociedad conformada como democrática, justa, libre y plural (art. 1.1 CE); y a su luz, que ésta y la seguridad hayan de plantearse sin caer en el riesgo mismo, y paradójico, del miedo al general riesgo que nos embarga $^{10}$, de forma que ambas limiten desproporcionada y arbitrariamente los fundamentos del orden democrático y de Derecho al que han de servir y asegurar (y en particular, la libertad); es más, la propia seguridad nacional hoy se concibe al servicio de la protección de «la libertad, los derechos y bienestar de los ciudadanos» (art. 3 L 36/2015) ${ }^{11}$. La inteligencia, entonces, ha de concebirse, diseñarse, desarrollarse y ejecutarse desde dichos fundamentos, en especial al desenvolverse normalmente de manera constante y ordinaria, y consecuentemente que la inteligencia deba ser acompañada por las consiguientes garantías políticas y jurídicas a estos efectos.

\section{SERVICIOS DE INTELIGENCIA: CNI Y COMUNIDAD DE INTELIGENCIA}

La complejidad de esta sociedad tecnificada, global y del riesgo exige de una inteligencia cada vez más compleja, extensa, técnica y cooperativa (de «inteligencia abierta» se llega a hablar ${ }^{12}$; y al hilo de ello, una comunidad de inteligencia como organización pública y compuesta por distintos servicios y entidades a fin de obtener y analizar información, así como su difusión ${ }^{13}$. La inteligencia, por tanto, no resulta monopolizada, sino esparcida entre diversas instancias y servicios, sin perjuicio de

7 De interés, D. Navarro Bonilla, «El Ciclo de Inteligencia y sus límites», Cuadernos constitucionales de la Cátedra Fadrique Furió Ceriol, no 48, 2004, pp. 51 y ss.

8 P.e. A.M. DíAz FernáNDEZ, «El papel de la inteligencia estratégica en el mundo actual», Cuadernos de Estrategia, ${ }^{\circ} 162,2013$, pp. 35 y ss.; o S. BeAtriz CuCovaz, «Inteligencia estratégica», AA.VV. Conceptos fundamentales de inteligencia, Tirant lo Blanch, Valencia, 2016, pp. 241 y ss.

9 Cfr. G. Díaz Matey, «Hacia una definición inclusiva de inteligencia», Inteligencia y Seguridad, $\mathrm{n}^{\circ} 4$, 2008 , pp. 59 y ss.

10 Sobre dicho miedo y sus riesgos, F.J. De LuCas Martín, «El miedo en las sociedades más seguras de la historia», Anales de la Cátedra Francisco Suárez, n 43, 2009, pp. 85 y ss.

11 Y acerca de la tensión entre libertad y seguridad, E. Denninger, «Prevención y libertad. Sobre el orden de la libertad», F. Fernández-Crehuet (trad.), asimismo Anales de la Cátedra Francisco Suárez, no 43, 2009, pp. 39 y ss.

12 E.V. Iglesias, «Prólogo», AA.VV. Conceptos fundamentales de inteligencia... cit., p. 11.

13 Cfr. I.A. Rosales Pardo, «La inteligencia en los procesos de toma de decisiones en la seguridad y defensa», Cuadernos de Estrategia, n 130, 2005, pp. 44-45. 
reconocer, eso sí (en nuestro país), la preeminencia del Centro Nacional de Inteligencia $(\mathrm{CNI})^{14}$. En este sentido, la Ley 11/2002, de 6 de mayo, supuso cierta actualización del centro superior de la inteligencia española al marco constitucional y a las necesidades que conllevaba ya la sociedad del riesgo ${ }^{15}$, a la par que venía a establecer las bases para una comunidad de inteligencia eficiente, implicada y cooperativa aquí (en especial, con la Comisión Delegada del Gobierno para Asuntos de Inteligencia, art. 6 L 11/2002 ${ }^{16}$. A tales efectos el CNI se configuró como el organismo responsable de facilitar al Presidente del Gobierno (de manera individual) y al Gobierno (en su conjunto) «las informaciones, análisis, estudios o propuestas que permitan prevenir y evitar cualquier peligro, amenaza o agresión contra la independencia o integridad territorial de España, los intereses nacionales y la estabilidad del Estado de derecho y sus instituciones» (art. 1 L 11/2002) ${ }^{17}$; se conformó como un organismo público especial (disp. adic. $1^{a}$ L 11/2002) ${ }^{18}$, con cierta autonomía funcional para el cumplimiento de sus misiones (art. 7.2 L 11/2002) y con un régimen específico presupuestario, de contratación y de personal (art. 8 L 11/2002) ${ }^{19}$; y se integró en el ejecutivo mediante su adscripción al Ministerio de Defensa (originariamente art. $7.1 \mathrm{~L}$ 11/2002, y al tiempo disp. adic. segunda vigente RD 355/2018, de 6 de junio, por el que se reestructuran los departamentos ministeriales ${ }^{20}$, sin perjuicio de entender

14 C. Ruiz Miguel, «Problemas actuales del derecho de los servicios de inteligencia», Inteligencia $y$ Seguridad, $\mathrm{n}^{\circ} 2,2007$, pp. 30 y ss.

15 La L 11/2002 regula al CNI, sustituyendo al anterior CESID. Para una aproximación a la evolución de la inteligencia en España, vid. A.M. DíAz Fernández, «El servicio de inteligencia español a la luz de la teoría de la organización», Cuadernos constitucionales de la Cátedra Fadrique Furió Ceriol, no 48, 2004, pp. 19 y ss.; también, C. Ruiz Miguel, pero ahora «El CESID: Historia de un intento de modernización de los Servicios de Inteligencia», Arbor: Ciencia, pensamiento y cultura, n 709, 2005, pp. 121 y ss.

16 Vid. nuevamente A.M. DíAz Fernández, mas «Comunidad de inteligencia», AA.VV. Conceptos fundamentales de inteligencia... cit., 2016, pp. 59 y ss.

17 Para lo cual el Gobierno ha de determinar y aprobar anualmente los objetivos del CNI «mediante la Directiva de Inteligencia, que tendrá carácter secreto» (art. 3 L 11/2002), si bien los objetivos de ésta han de ser propuestos por la Comisión Delegada del Gobierno para Asuntos de Inteligencia (art. 6.4.a L 11/2002), y en la que precisamente participa el Director del CNI como Secretario (art. 6.2, in fine, L 11/2002). De este modo, el Gobierno ejerce un doble papel de dirección y consumidor de inteligencia, al definir políticamente objetivos, a la par que asume la inteligencia elaborada como criterio de decisión política al respecto de cuestiones relativas a los objetivos señalados. Y todo ello, a su vez, en relación con la más genérica Política de Seguridad Nacional, la cual, «bajo la dirección del Presidente del Gobierno y la responsabilidad del Gobierno» (art. 4.1 L 36/2015), se concreta como «Estrategia de Seguridad Nacional» (conteniendo «el análisis del entorno estratégico», especificando «los riesgos y amenazas que afectan a la seguridad de España», definiendo «las líneas de acción estratégicas en cada ámbito de actuación» y promoviendo «la optimización de los recursos existentes», según art. 4.3 L 36/2015).

$18 \mathrm{Vid}$. V. Moret Millás, «El Centro Nacional de Inteligencia: una aproximación a su régimen jurídico», Foro (Revista de Ciencias Jurídicas y Sociales. Nueva época), n 2, 2005, pp. 249 y ss.

$19 \mathrm{Vid}$. J. Llavador Piqueras e H. Llavador Cisternes, El Régimen Jurídico de los Servicios de Inteligencia en España, Tirant lo Blanch, Valencia, 2015, Cap. III.6, 7 y 8.

20 Recuérdese que la L 11/2002 prevé, mediante disposición reglamentaria del Presidente del Gobierno, la posibilidad de modificar la adscripción orgánica del CNI a favor de otro Ministerio (disp. adic. $3^{\mathrm{a}}$ ), como así resultó durante casi siete años: inicialmente, disp. adic. segunda RD 1823/2011, de 21 de diciembre; y ulteriormente, disp. adic. segunda RD 415/2016, de 3 de noviembre. Sobre tal deslegalización, 
que la labor del CNI exceda en mucho la defensa del Estado (conforme art. 8.1 CE) al abarcar cualquier riesgo emergente que pueda afectar a intereses generales del mismo y la sociedad española ${ }^{21}$. Respecto a la actividad del CNI, y al servicio de los objetivos genéricos señalados a éste (art. 1 L 11/2002), el artículo 4 de la referida Ley $11 / 2002$ concreta sus funciones, mientras el 2 define una serie de principios como son su sometimiento al ordenamiento jurídico y al control parlamentario y judicial (además de los de «eficacia, especialización y coordinación»); por otra parte el artículo 5.1 se refiere a su carácter de secreto, y el 5.5 lo autoriza, en el cumplimiento de sus funciones, a «llevar a cabo investigaciones de seguridad sobre personas o entidades» (y pudiendo, al respecto, «recabar de organismos e instituciones públicas y privadas la colaboración precisa»).

En cuanto al resto de la comunidad de inteligencia española, y si bien todavía en el ámbito del CNI, está el Centro Criptológico Nacional $(\mathrm{CCN})^{22}$. A nivel militar, ahora, se encuentra el Centro de Inteligencia de las Fuerzas Armadas $\left(\right.$ CIFAS) ${ }^{23}$, integrado en el Estado Mayor de la Defensa (art. 9.3.b RD 872/2014, de 10 de octubre, por el que se establece la organización básica de las Fuerzas Armadas $)^{24}$ y actuando hoy como único servicio en materia de inteligencia militar a nivel estratégico ${ }^{25}$. Y como inteligencia policial, en el seno del Ministerio

J.F. SÁNCHEZ BARRILAo, De la ley al reglamento delegado (Deslegalización, acto delegado y transformaciones del sistema de fuentes), Thomson Reuters / Aranzadi, Cizur Menor (Navarra), 2015, pp. 185 y ss., y esp. 192.

21 No en vano, la LO 5/2005, de 17 de noviembre, de la Defensa Nacional, en su Tít. V («Contribución a la defensa»), dedica expresamente su Cap. III (art. 26) al CNI [gráficamente, entre la Guardia Civil y la Policía Nacional (respectivamente, Caps. II y IV)]; mientras, la L 36/2015 (recuérdese) reduce «los Servicios de Inteligencia e Información» (más sin mencionar expresamente al CNI) a mero apoyo del Sistema de Seguridad Nacional (art. 9.2), del que sí forman parte «la Defensa Nacional, la Seguridad Pública y la Acción Exterior» (art. 9.1). Otra cuestión es si la autonomía institucional del CNI (art. 7.2 L 11/2002) supone la sustracción de éste tanto de las Fuerzas Armadas, como de las Fuerzas y Cuerpos de Seguridad del Estado, quedando en un ámbito diverso (e indeterminado), aunque en estrecha relación a ambos; así parece resultar a la vista de la Sentencia de la Sección 15 de la Audiencia Provincial de Madrid, de 16 de julio de 2018, en la que, con relación a un presunto delito de injurias a los «Ejércitos, Clases o Cuerpos y Fuerzas de Seguridad» (art. 504.2 CP), expresamente se niega la condición del CNI como objeto pasivo del mismo al no ser uno de ellos (FD n $\mathrm{n}^{\circ} 2$, in fine).

22 De manera más concreta, RD 421/2004, de 12 de marzo (en virtud de disp. final primera L 11/2002), de acuerdo al cual el CCN queda adscrito al CNI, compartiendo con él medios, procedimientos, normativa y recursos, y rigiéndose asimismo por la L 11/2002 (art. 2.3 RD 421/2004).

23 De interés, J. Jiménez Ruiz «La racionalización de la inteligencia en las Fuerzas Armadas», Cuadernos de Estrategia, $\mathrm{n}^{\circ} 130,2005$, pp. 143 y ss. (y esp. 159 y ss.).

24 En especial, vid. art. 14.1, 2 y 3 RD 872/2014; también, arts. 5.1.c y 10 Orden DEF/166/2015, de 21 de enero, por la que se desarrolla la organización básica de las Fuerzas Armadas.

25 Respecto a los cometidos específicos del CIFAS, y a su estructura (que serán establecidos por el Ministro de Defensa), éstos se consideran «secreto» (disp. adic. $1^{\text {a }}$ RD 872/2014; también, art. 10 Orden DEF/166/2015). En relación con la ciberdefensa, en el mismo Estado Mayor de la Defensa (y junto al CIFAS) se encuentra el Mando Conjunto de Ciberdefensa (arts. 9.3.c y 15 RD 872/2014, y 1.1.d y 3 Orden DEF/1887/2015, de 16 de septiembre, por la que se desarrolla la organización básica del Estado Mayor de la Defensa). Y en un escalón operacional (y junto al CIFAS, y en el Estado Mayor del Mando de Operaciones) se encuentra el Área de Operaciones, con una Sección de Inteligencia (arts. 14.1 RD 872/2014 y 2.3.a Orden $\mathrm{DEF} / 1887 / 2015)$. 
del Interior operan el Cuerpo Nacional de Policía y la Guardia Civil (art. 9 LO 2/1986, de 13 de marzo, de Fuerzas y Cuerpos de Seguridad, y ambas bajo la Dirección General de la Policía y la Dirección General de la Guardia Civil en el ámbito de la Secretaría de Estado de Seguridad, conforme art. 1.5.a. $1^{\circ}$ y $2^{\circ} \mathrm{RD}$ 952/2018, de 27 de julio, por el que se desarrolla la estructura orgánica básica del Ministerio del Interior $)^{26}$ : concretando en el primero, están la Dirección General de aquélla y su Dirección Adjunta Operativa (art. 3.1 y 2.a RD 952/2018) ${ }^{27}$, y en su seno (art. 3.3 RD 952/2018) la Comisaría General de Información, la Comisaría General de Policía Judicial y la Comisaría General de Extranjería y Fronteras; y al respecto de la Guardia Civil, y dentro de su Dirección General y de su Dirección Adjunta Operativa (art. 4.1, 3.a y 6 RD 952/2018), el Mando de Operaciones, del que a su vez dependen la Jefatura de Información, la Jefatura de Policía Judicial, y la Jefatura Fiscal y de Fronteras ${ }^{28}$; por último, y como órgano de coordinación (de ambos cuerpos) y con nivel orgánico de subdirección general (art. 2.3.c RD 952/2018), está el Centro de Inteligencia contra el Terrorismo y el Crimen Organizado (CITCO), recepcionando, integrando y analizando información estratégica al respecto de la delincuencia organizada (o grave), el terrorismo y el radicalismo violento ${ }^{29}$. En el marco policial autonómico (y al amparo del art. 149.1.29 ${ }^{a}$ CE, y Títs. III y IV LO 2/1986) ${ }^{30}$, se encuentran: en el seno de la Ertzaintza (Policía Autonómica del País Vasco), la Oficina Central de Inteligencia, directamente dependiente de la Jefatura de aquélla ${ }^{31}$; respecto a los Mossos D'Esquadra (Policía Autonómica de Cataluña), la Comisaría General de Información ${ }^{32}$; y en relación con la Policía Foral Navarra, e integrada en el Área de Investigación Criminal, la División de Información ${ }^{33}$.

Por otra parte, y al margen de la inteligencia relativa a defensa y seguridad pública, se advierten otros organismos como son: dentro del Ministerio de Hacienda (y en él la Agencia Estatal de Administración Tributaria, art. 2.4 RD

$26 \mathrm{Y}$ arts. 6.2 RD 355/2018, de 6 de junio, por el que se reestructuran los departamentos ministeriales, y 5.A. $1^{\circ}$ y $2^{\circ}$ RD 595/2018, de 22 de junio, por el que se establece la estructura orgánica básica de los departamentos ministeriales.

27 También, la División de Cooperación Internacional (art. 3.2.e RD 952/2018).

28 Además, la Secretaría de Cooperación Internacional (art. 4.5 RD 952/2018).

29 Así como el diseño de estrategias contra estas amenazas y su financiación, como el establecimiento de criterios de actuación y coordinación operativa en supuestos de coincidencia o concurrencia en las investigaciones; del CITCO también depende la Oficina Nacional de Información sobre Pasajeros (art. 2.3.c, in fine, RD 952/2018).

30 De manera crítica a una extensión de la inteligencia autonómica más allá de un ámbito estrictamente policial, vid. M. Revenga SÁnchez y A. M. Díaz Fernández, « ¿Servicios de inteligencia autonómicos?», Claves de la Razón Práctica, no 198, 2009, pp. 46 y ss.

31 Arts. II.2 y V Orden de 20 de noviembre de 2013, de la Consejera de Seguridad, por la que se aprueba la estructura de la Ertzaintza.

32 Art. 48.1 D 415/2011, de 13 de diciembre, de estructura de la función policial de la Dirección General de la Policía.

33 Arts. 23.1 y 2.c, y 26 DF 72/2016, de 21 de septiembre, por el que se aprueba el reglamento de organización y funcionamiento de la Policía Foral de Navarra. 
1113/2018, de 7 de septiembre, por el que se desarrolla la estructura orgánica básica del Ministerio de Hacienda), el Servicio de Vigilancia Aduanera ${ }^{34}$; o en el seno del Ministerio de Economía y Empresa, la Secretaría de Estado de Economía y Apoyo a la Empresa (art. 1.3.A RD 1046/2018, de 24 de agosto, por el que se desarrolla la estructura orgánica básica del Ministerio de Economía y Empresa), con la Dirección General de Tesoro y Política Financiera (art. 4.1.i RD 1046/2018 $)^{35}$, y la Comisión de Prevención del Blanqueo de Capitales e Infracciones Monetarias, el Comité de Inteligencia Financiera y el Servicio Ejecutivo de la Comisión de Prevención del Blanqueo de Capitales e Infracciones Monetarias $^{36}$. En el ámbito ahora de la protección civil y la anticipación de riesgos y amenazas se encuentra la Red Nacional de Información sobre Protección Civil ${ }^{37}$, y concretando en las infraestructuras críticas el Centro Nacional para la Protección de las Infraestructuras Críticas (CNEPIC) ${ }^{38}$, además de, y a nivel ya de la ciberseguridad, los equipos de respuesta a incidentes de seguridad informática de referencia $(\text { CSIRT })^{39}$. Para finalizar, al respecto de la acción exterior del Estado y

34 A su vez encuadrado en la Dirección Adjunta de Vigilancia Aduanera de la Agencia Tributaria (art. $5^{\circ}$ Orden de 2 de junio de 1994 por la que se desarrolla la estructura de la Agencia Estatal de Administración Tributaria); sobre sus funciones, arts. 2 RD 319/1982, de 12 de febrero, por el que se reestructura y adscribe directamente el Servicio de Vigilancia Aduanera, y 7.1.x.7 Orden PRE/3581/2007, de 10 de diciembre, por la que se establecen los departamentos de la Agencia Estatal de Administración Tributaria y se les atribuyen funciones y competencias.

35 Y dentro de dicha Dirección, la Subdirección General de Inspección y Control de Movimientos de Capitales (art. 4.2.c RD 1046/2018).

36 Asimismo a la luz de la L 10/2010, de 28 de abril, de prevención del blanqueo de capitales y de la financiación del terrorismo (disp. final primera) está la Comisión de Vigilancia de Actividades de Financiación del Terrorismo (ya, L 12/2003, de 21 de mayo, de prevención y bloqueo de la financiación del terrorismo, art. 9), si bien adscrita al Ministerio del Interior (RD 413/2015, de 29 de mayo, por el que se aprueba el Reglamento de la Comisión de Vigilancia de Actividades de Financiación del Terrorismo).

37 Integrada en el Sistema Nacional de Protección Civil y gestionada por el Centro Nacional de Seguimiento y Coordinación de Emergencias de Protección Civil (encuadrado en la Dirección General de Protección Civil y Emergencias, Subsecretaría de Interior del Ministerio del Interior); arts. 1.1 y 5.b.4º 8.2.g y 4.d, y 12 RD 952/2018 (asimismo hoy, art. 5.B.4 RD 595/2018). Le corresponde a esta Red «los análisis y estudios que permitan obtener información y predicciones sobre situaciones peligrosas» (arts. 3.1.a, 8, 9 y $18 \mathrm{~L}$ 17/2015, de 9 de julio, del Sistema Nacional de Protección Civil).

38 Integrado en la Secretaría de Estado de Seguridad del Ministerio del Interior (arts. 6 y 7.2 L 8/2011, de 28 de abril, por la que se establecen medidas para la protección de las infraestructuras críticas, y art. 7 RD 704/2011, por el que se aprueba el Reglamento para la Protección de las Infraestructuras Críticas), y la Comisión Nacional para la Protección de las Infraestructuras Críticas y el Grupo de Trabajo Interdepartamental para la Protección de las Infraestructuras Críticas (arts. 3.2.g y h, 10.2, 11 y 12 L 8/2011, y esp., y respectivamente, arts. 11 y 12 RD 704/2011).

39 Art. 12.2.d RD-ley 12/2018, de 7 de septiembre, de seguridad de las redes y sistemas de información. Además de los referidos CCN y Mando Conjunto de Ciberdefensa (como CCN-CERT y ESPDEF-CERT), está el Instituto Nacional de Ciberseguridad de España (como INCIBE-CERT, art. 11.1.a RD-ley 12/2018), operando conjuntamente por el CNPIC (arts. 2.3.a.11 ${ }^{\circ}$ RD 952/2018 y 9.1.a.1 ${ }^{\circ}$ RD-ley 12/2018) y el Instituto Nacional de Ciberseguridad (anteriormente Instituto Nacional de Tecnologías de la Comunicación, y hoy sociedad dependiente del Ministerio de Economía y Empresa a través, entendemos, de la Secretaría de Estado para el Avance Digital conforme art. 8 RD 1046/2018, de 24 de agosto, por el que se desarrolla la estructura orgánica básica del Ministerio de Economía y Empresa). 
dentro del Ministerio de Asuntos Exteriores, Unión Europea y Cooperación, está la Dirección General de Comunicación e Información Diplomática (art. 22 RD 1271/2018, de 11 de octubre, por el que se desarrolla la estructura orgánica básica del Ministerio de Asuntos Exteriores, Unión Europea y Cooperación y por el que se modifica el Real Decreto 595/2018, de 22 de junio, por el que se establece la estructura orgánica básica de los departamentos ministeriales) ${ }^{40}$.

\section{INTELIGENCIA, SECRETO Y ESTADO DE DERECHO}

La actual extensión de la actividad de inteligencia a cualquier fenómeno o actuación que suponga un riesgo o amenaza grave para los intereses generales del Estado, la sociedad española y los derechos de los ciudadanos, así como la institucionalización y organización de la inteligencia en una amplia y compleja comunidad (conforme se acaba de señalar), es que confiera a ésta una capacidad tal de acción que requiera, en contrapartida, de efectiva limitación y control a fin de garantizar su sujeción a los fundamentos del sistema político y jurídico del Estado en cuanto que social y democrático de Derecho (art. 1.1 CE); y ello, ante el referido riesgo que pueda suponer un servicio de inteligencia sin fiscalización para los fines a los que sirve, y especialmente al respecto de los derechos fundamentales ${ }^{41}$. En este sentido, la Ley 11/2002 sujeta expresamente la actuación del CNI «a control parlamentario y judicial» (art. 2.2) ${ }^{42}$, como manifestación ineludible de la doble consideración del Estado, y de sus poderes, como democrático y de Derecho (nuevamente art. 1.1 CE) ${ }^{43}$; y así desde una concepción de la democracia pluralista y al hilo de un sistema jurídico protector de los derechos fundamentales y las libertades de los individuos (y con ello de las propias minorías), y por tanto garante de la efectiva participación de los ciudadanos (directa o indirectamente) en la toma y en el control de las decisiones políticas ${ }^{44}$. Pero antes de entrar en tal

40 De manera específica, Subdirección General de la Oficina de Información Diplomática (art. 22.2.a RD 1271/2018); además están las Consejerías de Interior en las Misiones Diplomáticas de España (art. 4.1.d RD 1300/2006, de 10 de noviembre, sobre organización y funciones de las Consejerías de Interior en las Misiones Diplomáticas de España).

41 Con carácter general, C. Ruiz Miguel, Servicios de Inteligencia y Seguridad del Estado Constitucional, Tecnos, Madrid, 2003, Cap. I.

42 Sigue diciendo el art. 2.2 L 11/2002: «[...] en los términos que esta Ley y la Ley Orgánica reguladora del control judicial previo del Centro Nacional de Inteligencia determinan». No obstante, de manera crítica a tal diseño por sus limitaciones (y sin perjuicio de volver a ellas más adelante), vid. M. REvENGA SÁNCHEZ, «El control del Centro Nacional de Inteligencia», Claves de Razón Práctica, n 130, 2003, pp. 40 y ss.

43 Además del 1.2 CE, en razón a la consideración del poder como constituido y limitado; cfr. F. BALAguer Callejón, Fuentes del Derecho (II), Tecnos, Madrid, 1992, pp. 31 y ss.

44 Cfr. J.M. Bilbao Ubillos, «Los derechos humanos en las democracias contemporáneas», AA.VV. Los desafíos de los derechos bumanos hoy, Dykinson, Madrid, 2007, pp. 97 y ss. Y al hilo de ello, la consideración de la inteligencia como indicador de efectiva democracia, según cómo se desarrolle precisamente tal control; cfr. G. DíAz MAtey, «Conceptions of Intelligence: Intelligence as a Democratic 
control (especialmente el judicial), esencial nos resulta aproximarnos a la configuración secreta que de buena parte sobre la inteligencia pesa, por cuanto que allí donde hay secreto difícil, como poco, resulta su fiscalización; y esto desde cierto carácter reservado que sin embargo sobre la información, como sobre la actividad y la organización de la inteligencia se requiere a fin de su efectividad (arts. 103.1 y 105.b CE $)^{45}$. En tal sentido, e insistimos, si el control es esencial en el Estado democrático y de Derecho, no lo puede ser menos el carácter público del ejercicio del poder público ${ }^{46}$, de modo que su limitación va a exigir de una ineludible justificación constitucional: a estos efectos, la exigencia del mantenimiento de un ámbito al margen del acceso abierto a la ciudadanía de la actividad pública ${ }^{47}$ en tanto que absolutamente necesario para el normal desenvolvimiento del propio sistema democrático ${ }^{48}$; y de esta forma, entonces, que el secreto haya de plantearse más allá de la tradicional configuración arcana de la inteligencia, para afrontan su régimen constitucional ante la más genérica publicidad.

Un elemento clave en la transformación del Estado absoluto al liberal fue el paso de una caracterización secreta del ejercicio del poder a otra más abierta y pública, para finalmente proyectar su mayor intensidad con ocasión del desarrollo del Estado constitucional y democrático de Derecho que prospera tras la II Guerra Mundial ${ }^{49}$; mas, y como consecuencia de aquélla y la ulterior guerra fría, el mantenimiento del secreto (incluso su reforzamiento) al respecto de la defensa y la seguridad ${ }^{50}$. A este contradictorio modelo ${ }^{51}$, precisamente, respondería la Constitución española de $1978^{52}$ : así, en cuanto a la actividad de los poderes

Indicator», RIEAS: Research Paper, $\mathrm{n}^{\circ}$ 165, 2014, http://www.rieas.gr/images/publications/rieas165.pdf $(22 / 08 / 2018)$.

45 Vid. J.A. Santamaría Pastor, Principios de Derecho Administrativo (I), CEURA, Madrid, 1998, p. 112.

46 Por todos, F.J. De Lucas MarTín, «Democracia y transparencia. Sobre poder, secreto y publicidad», Anuario de Filosofía del Derecho, nº 7, 1990, pp. 131 y ss.

$47 \mathrm{Al}$ respecto de un cierto «secreto por prudencia», C. Ruiz MiguEL, «Secreto de Estado», AA.VV. Conceptos fundamentales de inteligencia... cit., pp. 335 y ss.

48 Así, p.e., STEDH de 4 de diciembre de 2008, en el asunto S. y Marper v. Reino Unido (30562/04 y 30566/04): «Una injerencia se considera «necesaria en una sociedad democrática» para alcanzar un fin legítimo si responde a una «necesidad social imperiosa» y en particular, si es proporcionada al fin legítimo perseguido y si los motivos invocados por las autoridades nacionales para justificarla parecen «pertinentes y suficientes»» $(\$ 101)$.

49 Por cuanto que: de un lado, democracia pluralista (con reconocimiento y garantía, así, de las minorías políticas); y de otro, efectivo reconocimiento y garantía jurídico-constitucional de un campo de derechos y libertades dispuestos en torno a la dignidad de la persona. Vid. P. HäBERLE, «La sociedad abierta de los intérpretes constitucionales: una contribución para la interpretación pluralista y «procesal» de la Constitución», X. Arzoz Santiesteban (trad.), en Retos actuales del Estado constitucional, IVAP, Oñati, 1996, pp. 15 y ss.

$50 \mathrm{Vid}$. M. Revenga Sánchez, El imperio de la política (Seguridad nacional y secreto de Estado en el sistema constitucional norteamericano), Ariel, Barcelona, 1995, pp. 42 y ss.

51 Sobre tal paradoja, $c f r$. L.P. FRANCESCUTTI, «Regímenes del secreto y sociedad de la información», Letra. Imagen. Sonido: Ciudad Mediatizada, $\mathrm{n}^{\circ} 13,2015$, pp. 157-159.

52 En general, acerca del régimen constitucional del secreto en la CE de 1978, vid. L.M. DíEz-PiCAzo, «Publicidad y secreto en la Constitución», Sobre secretos oficiales, Civitas, Madrid, 1998, pp. 77 y ss. 
públicos, ésta prevé expresamente la publicidad de las normas (arts. 9.3, 82.3, 91 y 96.1), la publicidad procesal o jurisdiccional (arts. 24.2, 120.1 y 3 , y 164.1), la publicidad parlamentaria (art. 80) y el propio acceso de los ciudadanos a la información y a los registros públicos (art. 105.b); y de otro, y como excepción a lo anterior, el secreto jurisdiccional (art. 120.1), el secreto parlamentario (art. 80) y la prohibición de acceso a cierta información y registros públicos (nuevamente, y sin embargo, art. 105.b). De este modo se expresa el acceso de los ciudadanos a la información que posee la Administración, facilitando el control por éstos sobre la actuación de aquélla ${ }^{53}$, pero por otro lado se viene a limitar expresamente tal acceso cuando «afecte a la seguridad y defensa del Estado» (otra vez, art. 105.b); pero con ello infiltrándose constitucionalmente la seguridad y la defensa, y con éstas la misma inteligencia, más allá del propio acceso a la información, para alcanzar y excepcionar entonces transversalmente la publicidad jurisdiccional, parlamentaria e incluso normativa.

Mientras, y al respecto de los ciudadanos, parecería invertirse los anteriores términos, de manera que ahora se garantizaría constitucionalmente el silencio (arts. 16.1 y 2, y 24.2) y el secreto (arts. 18; 20.1.d y 24.2; 68.1, 69.2 y 140; y 105.b) para aquéllos, salvo determinados contenidos y actividades (art. 22.3 y 5). Y con esto, también, la restricción genérica y abstracta de la actuación de la inteligencia con relación a tales silencios y secretos de las personas, mas sin perjuicio de su legítima limitación; de ahí, la exigencia de control sobre la inteligencia no ya a nivel político, sino especialmente de tipo judicial en tanto que garantía efectiva de los derechos y libertades afectados (según se viene a mostrar en los siguientes epígrafes).

Además, la progresiva ampliación de la noción de seguridad a la sombra de la sociedad del riesgo va a dar lugar a una consiguiente extensión del secreto en lo público, así como, y en contrapartida, a una mayor capacidad de la inteligencia ante lo privado. Si tradicionalmente el secreto se conectaba con la defensa y con muy determinadas parcelas de la seguridad pública (como el terrorismo), hoy la consideración de la seguridad alcanza una mayor parcela de la actividad pública y privada (art. 6 L 36/2015); y con ello que el binomio secreto y seguridad (e inteligencia) genere un peligroso obstáculo (aun legítimo) para la democracia y la efectiva fiscalización de la actuación de los poderes públicos ${ }^{54}$. No obstante, y específicamente al respecto de la inteligencia y del propio CNI, es que el Tribunal Constitucional, en su Sentencia 31/2014 de 24 de febrero, haya considerado que la clasificación como secreto de una materia «no puede suponer un espacio de inmunidad al control jurisdiccional» (FJ núm. 6) ${ }^{55}$. Sin perjuicio de volver a ello

53 Cfr. STS, Sala de lo Contencioso (Sec. 6), 2206/1999, de 30 de marzo (FD no 3 ).

54 Cfr. A. Ава Catorra, «El secreto de Estado y los servicios de inteligencia», Cuadernos constitucionales de la Cátedra Fadrique Furió Ceriol, nº 38/39, 2002, esp. pp. 134-136.

55 Sigue diciendo el Tribunal: «[...] en este sentido, la STEDH de 15 de noviembre de 1996, caso Chabal c. Reino Unido, afirma que «el Tribunal reconoce que el uso de información de carácter confidencial 
más adelante, es esencial destacar desde este momento cómo el Tribunal Constitucional rechaza un binomio incondicional de secreto-inmunidad para los poderes públicos, y por tanto que el secreto no deba/pueda considerarse en ningún caso como un concepto absoluto. A esta idea habría que añadir la reflexión previa que hemos hecho más arriba a favor del principio de publicidad y del carácter excepcional del secreto ${ }^{56}$, de forma que éste deberá justificarse conforme a estrictos criterios de razonabilidad y proporcionalidad ${ }^{57}$, además de rigurosamente finalista en razón a la seguridad nacional ${ }^{58}$.

En cuanto al desarrollo normativo del secreto, éste sigue centrándose en la preconstitucional Ley 9/1968, de 5 de abril, sobre secretos oficiales (conforme reforma por L 48/1978, de 7 de octubre $)^{59}$, y complementada al tiempo por la Ley 11/1995, de 11 de mayo, reguladora de la utilización y control de los créditos destinados a gastos reservados ${ }^{60}$. Respecto a la Ley 9/1968, y después de afirmar con carácter general la publicidad de la actividad pública (art. 1.1), ésta prevé el secreto en la misma ${ }^{61}$, correspondiendo su clasificación exclusivamente

puede ser inevitable cuando se halla en juego la seguridad nacional. Pero eso no implica que las autoridades nacionales hayan de quedar libres de controles efectivos por parte de los tribunales nacionales siempre que afirmen estar ante un problema de seguridad nacional o de terrorismo» (párrafo 131)».

56 Así, M.P. García Bossio, «Secreto de Estado. Los límites de la democracia», Apuntes de Investigación del CECYP, n 29, 2017, esp. pp. 161 y ss.

57 Desde esta perspectiva restrictiva, $c f r$.: E. Álvarez Conde, «Secretos de Estado y Constitución», Revista Galega de Administración Pública, n 25, 2000, p. 30; y M.P. Cousido GONZÁLEZ, «Secretos de Estado: cambios reales, políticos y legales en la era de la transparencia», Revista Jurídica de Castilla y León, n $^{\circ} 33,2014$, p. $6 / 23$.

58 Cfr. Á.L. Alonso de Antonio, «La Ley de secretos oficiales», Foro, Nueva época, vol. 18, n 1 , 2015 , p. 222.

59 Sobre la originaria L 9/1968, y su reforma de 1978, vid. L.A. Pomed SÁNCHEZ, «Transparencia», Fundamentos: Cuadernos Monográficos de Teoría del Estado, Derecho Público e Historia Constitucional, no 9, 2017, pp. 179 y ss., y 183 y ss. (respectivamente).

60 Más recientemente, Proposición de Ley de reforma de la Ley 9/1968, de 5 de abril, sobre secretos oficiales (122/000021), presentada en el Congreso de los Diputados el 7 de septiembre de 2016 por el Grupo Parlamentario Vasco (Boletín Oficial de las Cortes Generales, Congreso de los Diputados, XII Legislatura, Serie B: Proposiciones de Ley, 16 de septiembre de 2016, $\mathrm{n}^{\circ}$ 32-1). Dicha proposición fue abierta a numerosos plazos de ampliación de enmiendas, pasando a fase de informe en la Comisión Constitucional y resultando finalmente caducada su tramitación conforme acuerdo de la Mesa de la Diputación Permanente del Congreso de 13 de marzo de 2019, una vez producida la disolución de la Cámara (Boletín Oficial de las Cortes Generales, Congreso de los Diputados, XII Legislatura, Seria D: General, de 27 de marzo de 2019, nº 519, relación A.10). En cuanto a las enmiendas, se presentaron 53 (Boletín Oficial de las Cortes Generales, Congreso de los Diputados, XII Legislatura, Serie B: Proposiciones de Ley, 11 de abril de 2018, nº 32-4). Una Proposición (y unas enmiendas), por cierto, bastantes más limitadas a parchear la L 9/1968, que a establecer un nuevo régimen jurídico sobre los secretos oficiales. Sobre dicha propuesta, F. MARTínEZ VÁzQUEZ, «El control parlamentario de los secretos oficiales», Revista de las Cortes Generales, no 104, 2018, pp. 406, y 416 y ss. También, para una aproximación a una propuesta de reforma previa (Anteproyecto de Ley Orgánica regulador de Secretos de Estado de 23 de agosto de 1996), vid.: R. LASAga SANZ, «Secretos de Estado y Constitución: Fundamentos y técnicas de control», RVAP, n 54, 1999, pp. 97-98; y J.J. DíEz SÁnCHEz, Razones de Estado y Derecho, Tirant lo Blach, Valencia, 1999, pp. 299 y ss.

61 Si bien distinguiendo entre materias que sean clasificadas secretas conforme a dicha L 9/1968 (art. 1.1), de las que sean expresamente declaradas secretas por otra ley (art. 1.2); y a los efectos de la clasificación 
al Gobierno (art. 4$)^{62}$ y no pudiendo esta facultad ser transferida ni delegada (art. 5); por otra parte, la cancelación sólo podrá ser dispuesta por aquél (art. 7), y sin preverse plazo alguno de desclasificación automática ${ }^{63}$. Naturalmente sobre el secreto existe el deber de guardar secreto y custodia (arts. 9.1, 11.1, 12 y 14), llegándose a tipificar penalmente su quebranto (arts. 598 a 603 CP). Y en cuanto a la Ley 11/1995, que los fondos reservados «que se consignen como tales en las Leyes de Presupuestos Generales del Estado y que se destinen a sufragar los gastos que se estimen necesarios para la defensa y seguridad del Estado» ${ }^{64}$, se caractericen frente «a los demás gastos públicos por la prohibición de publicidad» (art. 1); y al hilo de los mismos, extendiéndose tal régimen a toda información «correspondiente a su utilización efectiva» $(\text { art. } 3)^{65}$.

De manera más concreta ahora sobre el secreto y la inteligencia, y empezando por el CNI, la Ley 11/2002 declara directa y expresamente como secreto tanto la Directiva de Inteligencia que ha de aprobar el Gobierno anualmente, y donde se marcan los objetivos del CNI (art. 3), como sus actividades, «organización y estructura interna, medios y procedimientos, personal, instalaciones, bases y centros de datos, fuentes de información y las informaciones o datos que puedan

como secreta, que recaiga sobre «asuntos, actos, documentos, informaciones, datos y objetos cuyo conocimiento por personas no autorizadas pueda dañar o poner en riesgo la seguridad y defensa del Estado» (art. 2). Sobre las categorías del secreto, la L 9/1968 distingue entre lo secreto y lo meramente reservado «en atención al grado de protección que requieran» (art. 3), a cuyo fin se diversifica su régimen (art. 8) y se remite a un reglamento su desarrollo (art. 10.1 y disp. final; y a tales efectos, D 242/1969, de 20 de febrero, por el que se desarrollan las disposiciones de la L 9/1968).

62 Y a la Junta de Jefes de Estado Mayor, según art. 4 (nuevamente). No obstante, adviértase que dicho órgano en la actualidad no existe; así, vid. nuevamente M.P. Cousıdo GonZÁLEZ, op. cit., p. 5/23.

63 Únicamente, y «[a] efectos de evitar la acumulación excesiva de material calificado, la autoridad encargada de la calificación deberá señalar los procedimientos para determinar, periódicamente, la conveniencia de la reclasificación o desclasificación de aquel material» (art. 3.IV D 242/1069). Diversa es la referida propuesta de reforma de la L 9/1968 presentada por el Grupo Vasco, en la que se establecía 25 años máximo para materias calificadas secretas y 10 para las calificadas reservadas, «salvo que el Consejo de Ministros disponga su prórroga excepcional y motivada, en el exclusivo caso de las materias secretas, por un nuevo período máximo» de 10. Las señaladas enmiendas también venían a fijar diversos sistemas de plazos (enmiendas 1, 3 , $10,11,13,24$ y 40$)$.

64 Con carácter general, sobre los gastos reservados y la L 11/1995, C. LuCAS IÑIGO, «Gastos reservados», AA.VV. Conceptos fundamentales de inteligencia... cit., pp. 191 y ss.

65 Por otra parte, dichos fondos únicamente podrán consignarse «a gastos reservados en los Ministerios de Asuntos Exteriores y Cooperación, Defensa, Interior y en el Centro Nacional de Inteligencia dependiente del Ministerio de la Presidencia» (art. 4.1); y por tanto, que quepa cabalmente considerar como fondos reservados (y secretos) a los efectos de la inteligencia, cuando ésta se lleve a cabo en el seno de tales Ministerios y del CNI. En cuanto a otras manifestaciones legales del secreto en relación con la inteligencia y la seguridad, pero a nivel autonómico ahora y policial, son: para el caso de la Ertzaintza, la previsión (al hilo del modelo estatal definido por L 11/1995) de que los gastos destinados a la prevención y persecución de la criminalidad en el País Vasco tengan carácter reservado, conforme a la L 5/1997, de 30 de mayo, reguladora de Utilización y Control de los Créditos Destinados a Gastos Reservados del País Vasco; y al respecto de los Mossos D'Esquadra, e igualmente, que los créditos destinados a garantizar la seguridad y actuaciones relativas a la prevención y persecución criminal tengan la consideración de gastos reservados, según L 28/2001, de 31 de diciembre, de regulación de los créditos destinados a gastos reservados de la Administración de la Generalidad de Cataluña. 
conducir al conocimiento de las anteriores materias» (art. 5.1). En cuanto al CIFAS, el Real Decreto 872/2014 establece que sus cometidos específicos y estructura «se declaran «materia clasificada» en la categoría de «secreto», con arreglo a la [L 9/1968], y serán establecidos por el Ministro de Defensa» (disp. adicional primera). Y ya respecto al CITCO (y art. 2.3.c RD 952/2018), que su estructura resulte asimismo secreta a la sombra de dos Acuerdos de Consejo de Ministros de 16 de febrero de 1996 y de 6 de junio de $2014^{66}$. De otra parte, otras expresiones del secreto son el Acuerdo, de 15 de octubre de 2010, del Consejo de Ministros de España sobre Política de Seguridad de la Información del Ministerio de Asuntos Exteriores ${ }^{67}$; o a instancia de la Ley 19/2013, de 9 de diciembre, de transparencia, acceso a la información pública y buen gobierno, y al respecto de tal derecho de acceso (contradictoriamente), cómo éste puede verse sin embargo genéricamente limitado cuando su efectivo acceso suponga un perjuicio además para los intereses económicos y comerciales (art. 14.h) y la política económica y monetaria (art. 14.i) ${ }^{68}$; también se ha de tener en cuenta lo dispuesto por los Acuerdos internacionales, según se reconoce expresamente en la Ley 11/2002 (art. 5.1, in fine).

\section{INTELIGENCIA, CONTROL JURISDICCIONAL Y TUTELA JUDICIAL EFECTIVA}

Insistiendo en la efectiva limitación y fiscalización sobre la inteligencia a fin de garantizar su sujeción a los fundamentos del sistema político y jurídico del Estado en cuanto que social y democrático de Derecho (art. 1.1 CE), y al hilo de la expresa sujeción del CNI al control judicial (art. 2.2 L 11/2002, nuevamente), consideramos oportuno advertir cómo tal intervención y control judicial cabría plantearse desde un doble eje: uno, desde la división de poderes, y la difícil

66 Según la L 9/1968 una materia puede ser genéricamente declarada secreta mediante ley (nuevamente, art. 1.2), y por tanto con intervención directa hoy de las Cortes Generales (art. 66.1 CE); y así acontece entonces con la organización del CNI (art. 5.1 L 11/2002). Difícil de aceptar nos resulta, en cambio, el que la declaración de secreto de la organización del CIFAS se haga por mero Decreto (disp. adicional primera RD 872/2014), de modo que la norma que haya de regular ésta quede en el limbo del secreto (expresamente, art. 10 Orden DEF/166/2015); y desde luego menos aceptable es, y como acontece con el CITCO, que su estructura se deduzca secreta a partir de dos meros Acuerdos del Consejo de Ministros genéricamente referidos al terrorismo y al crimen organizado (de manera que ni siquiera se advierte públicamente del secreto de la regulación de su organización y funcionamiento). Y es que, conforme a los arts. 9.3 CE, 24.4 L 50/1997, de 27 de noviembre, del Gobierno, y 131 de la L 39/2015, de 1 de octubre, del Procedimiento Administrativo Común de las Administraciones Públicas, difícilmente cabe la condición de una norma reglamentaria como secreta sin previa y expresa previsión legal. Además, y más allá de los principios de publicidad normativa y seguridad jurídica (art. 9.3 CE, otra vez), está en juego el propio control jurisdiccional de la potestad reglamentaria (arts. 24.1 y $106.1 \mathrm{CE})$.

67 Vid. M.P. Cousido GonZÁlez, «Secretos de Estado... cit., p. 8/23.

68 Cfr. M.P. Cousido GonZÁleZ, op. cit., p. 12/23. 
posición del poder judicial como garante de la sujeción a Derecho al respecto de la actuación del Estado cuando de actos de máxima trascendencia política se trata; y otro, y sin embargo, la estrecha relación que nuestro sistema constitucional establece entre el poder judicial y la garantía de los derechos, y en particular de los derechos fundamentales y las libertades públicas. En tal sentido, y al tiempo, ha sido la segunda perspectiva la que ha prevalecido ${ }^{69}$; y ello, además, a tenor de la apertura de nuestro ordenamiento constitucional a sistemas de protección de derechos humanos a nivel supranacional, de forma que los jueces españoles acaban actuando en cuanto que garantes de aquéllos dada la dimensión multinivel en su reconocimiento y garantía ${ }^{70}$. De este modo es que el poder judicial, y al hilo de tal garantía de los derechos, se haya afianzado como un auténtico poder capaz de achantar a los otros políticos ${ }^{71}$, transformando (superando) su papel de mero controlador objetivo de la legalidad vigente ${ }^{72}$; y a estos efectos que la Constitución de 1978 haya depositado en Jueces y Magistrados (independientes en su sometimiento al imperio de la ley) la administración de la justicia que emana del pueblo (art. 117.1) a fin de procurar oportuna y efectiva garantía de los derechos y las libertades mediante la reserva exclusiva y excluyente de la potestad jurisdiccional a éstos (art. 117.3 y 4), a la par que mediante otras funciones no jurisdiccionales en garantía de derechos (art. 117.4, in fine): unas garantías, jurisdiccionales o no, que, y a tenor de su naturaleza, procuran una protección específica de singulares derechos fundamentales tanto violentados, como amenazados o potencialmente en peligro o riesgo en circunstancias concretas ${ }^{73}$.

En cuanto al control jurisdiccional sobre la inteligencia (específicamente), la garantía de la tutela judicial de los derechos e intereses que ella haya quebrado o con los que haya podido entrar en conflicto (art. 24.1 CE), como la plena y efectiva sujeción de la actividad pública a Derecho (art. 106.1 CE), implica así la posibilidad de su control jurisdiccional (art. 117.3 CE); e incluso, al hilo de la garantía extraordinaria para el caso de lesión de derechos fundamentales y libertades públicas que supone el recurso de amparo (conforme al art. 53.2 CE, y tal como lo ha puesto en evidencia la ya referida STC 31/2014), además del derecho a un recurso efectivo sobre los mismos (art. $13 \mathrm{CEDH}$ ). Recuérdese entonces cómo el Tribunal Supremo (Sala 3a) en tres Sentencias de 4 de abril de 1997 (recursos 602, 634 y 726/1996) vino a conocer de la legitimidad misma de la clasificación de una

69 Ya J.F. SÁnChez Barrilao, «On the constitutional position of judicial power in Spain: The judge as natural guarantor of rights», Jabrbuch des Öffentlichen Rechts, $\mathrm{n}^{\circ} 50,2002$, pp. 415 y ss.

70 P.e., vid. E. Guillén López, «Ejecutar en España las sentencias del Tribunal Europeo de Derechos Humanos. Una perspectiva de Derecho constitucional europeo», TRC, n 42, 2018, pp. 335 y ss.

71 Entre otros, M.Á. García Herrera, «Poder Judicial y Estado social: legalidad y resistencia constitucional», AA.VV. Corrupción y Estado de Derecho (El papel de la jurisdicción), Trotta, Madrid, 1996, pp. 59 y ss.

72 Cómo no, E. García De Enterría, «Contencioso-administrativo objetivo y contencioso-administrativo subjetivo a finales del Siglo XX», RAP, $\mathrm{n}^{\circ} 152,2000$, pp. 93 y ss.

$73 \mathrm{Vid}$. J.F. SÁNCHEz BARRILAO, «Límites a la atribución de funciones extrajurisdiccionales a jueces y magistrados», Cuadernos constitucionales de la Cátedra Fadrique Furió Ceriol, no 6, 1994, pp. 85 y ss. 
materia como secreto al resultar violentados derechos fundamentales tan importantes como la tutela judicial efectiva y el derecho a la vida, para llegar finalmente a estimar el recurso contencioso ante la limitada afección que suponía dicha clasificación para la seguridad del Estado ${ }^{74}$; y el 30 de enero de 1998, otra Sentencia del Tribunal Supremo (también Sala $3^{\mathrm{a}}$ ) en la que se entró en elementos discrecionales de la clasificación del secreto, y por tanto en si una desclasificación afectaba o no a la seguridad y/o a la defensa ${ }^{75}$. De ahí, al tiempo, la susceptibilidad abstracta de control jurisdiccional de actos políticos, como es precisamente la declaración de una materia como secreto ${ }^{76}$, cuando resulten vulnerados derechos fundamentales (así, art. 2.a L 29/1998, de 13 de julio, reguladora de la Jurisdicción Contencioso-administrativa $)^{77}$; y ello al respecto de los bienes constitucionales justificadores del secreto y de su clasificación (seguridad y defensa), como de aspectos formales de la declaración (procedimiento, competencia y motivación ${ }^{78}$. Otra cosa es la efectiva capacidad judicial, en tanto que limitada, respecto a materias que permanezcan legítimamente declaradas secretas y objeto de enjuiciamiento jurisdiccional con ocasión del testimonio de terceros e implicados, especialmente funcionarios públicos, a la sombra de la obligación de éstos de mantener reserva, de un lado (y la imposibilidad de obligarlos jurídicamente a testificar según art. 417.2 LECr) ${ }^{79}$, y a la luz, con todo, de que declaren voluntariamente, de otro ${ }^{80}$; e incluso al respecto de los mismos demandados o procesados, dada la condicionada capacidad del secreto (por sî) para articular su defensa ${ }^{81}$.

74 De interés, L.M. DíEz-PiCAzo, «La desclasificación del secreto de Estado: comentario a las Sentencias de la Sala $3^{\text {a }}$. del Tribunal Supremo de 4 de abril de 1997», Sobre secretos oficiales... cit., pp. 51 y ss.; y F. SANTAOlalla López, «Actos políticos, inteligencia nacional y Estado de Derecho», REDC, $\mathrm{n}^{\circ}$ 65, 2002, pp. 107 y ss. También, S. SÁnchez Ferro, El secreto de Estado, CEPC, Madrid, 2006, Parte III. Con todo, para un posicionamiento crítico a tal extensión del control jurisdiccional al respecto de actos políticos y especialmente referidos a la inteligencia, vid. C. RuIz Miguel, Servicios de Inteligencia y Seguridad del Estado Constitucional... cit., Cap. V.VII.3.

75 A. Ава Catoira, «El secreto de Estado y los servicios de inteligencia... cit., p. 163.

76 J. Jordano Fraga, « ¿Jaque mate al acto político?», REDA, n 95, 1997, pp. 417 y ss. También, J.J. DíEz SÁNCHEZ, op. cit., pp. 99 y ss., y 209 y ss.

77 Vid. L.J. Parejo Alfonso, «Artículo 2.a)», REDA, nº 100 (Ejemplar dedicado a: Comentarios a la Ley de la Jurisdicción Contencioso-Administrativa de 1998), 1998, pp. 57 y ss.

78 En tal sentido, cfr. S.A. Sото LosTAL, «Comentarios a la legislación española sobre secretos oficiales a la vista de la Sentencia de la Corte de Apelaciones del Distrito de Columbia (EE. UU.) de 21 de mayo de $2013 », R E D C, \mathrm{n}^{\circ} 111,2017$, pp. 379 y ss.

79 De manera que, para el caso de pruebas consideradas judicialmente como pertinentes y relevantes, quepa llegar a considerarse lesionado el derecho a la prueba (art. $24.2 \mathrm{CE}$ ); cfr. S. SÁNCHEZ FerRo, El secreto de Estado... cit., esp. p. 429.

80 Si bien con relación al proceso penal, vid. J.L. GonzÁLEZ CusSAC, «El secreto de Estado en el proceso penal: entre la denegación de auxilio y el delito de revelación», Inteligencia y Seguridad, $\mathrm{n}^{\circ}$ 12, 2012, pp. 141 y ss. Y a nivel jurisprudencial, la STEDH de 26 de julio de 2017, en el asunto $M$. v. the Netherlands (2156/10); otra cosa es que, con todo, en dicha STEDH se considerara lesionado los derechos de M. (miembro de un servicio secreto) a un juicio justo y a la defensa a través de abogado (art. 6.1 y 3 CEDH), como consecuencia de las limitaciones que a ellos supuso el secreto sobre su actividad.

81 Especialmente interesante, nuevamente S. SÁNCHEZ FERro, pero ahora «La última jurisprudencia de la Corte Costituzionale italiana en materia de secretos de Estado», TRC, n 31, 2013, esp. pp. 521 y ss. 
También de interés es la actuación indirecta de la actividad judicial sobre hechos no directamente atribuibles a la inteligencia pública (en sentido amplio), pero relativas a hechos en los que, y sin embargo, puede verse ésta implicada, de modo que, sin perjuicio del potencial control que sobre ello quepa darse, haya de garantizarse el debido secreto de aquella información que efectivamente afecte a la seguridad y a la defensa (art. 120.1 CE, además de arts. 232.3, 234.2, 476.1.f, 497.f y 542.3 LO 6/1985, de 1 de julio, del Poder Judicial), incluyendo la posibilidad de celebrar un juicio a puerta cerrada (expresamente, STS, Sala Segunda, de lo Penal, 1094/2010, de 10 de diciembre, FD núm. 1). Desde esta perspectiva, asimismo, cabría integrar el control jurisdiccional de actividad privada pero relativa a materia considerada secreta y en colaboración con la inteligencia pública ${ }^{82}$.

Igualmente de interés es el alcance territorial que sobre la acción judicial quepa darse en razón a actividades de la inteligencia española fuera del territorio español, como se derivaría expresamente al respecto del CNI (pues éste puede actuar fuera de España, según art. 4.a, in fine, L 11/2002). Ello, obviamente, ha de resolverse conforme a la aplicación de las correspondientes normas relativas al alcance territorial de la actividad judicial española (arts. 21 y ss. LO 6/1985), y especialmente a nivel penal (art. 23 LO 6/1985). Y asimismo, pero a la inversa, cabría apreciar la jurisdicción española al respecto de la actuación de inteligencias extranjeras en territorio nacional, sin perjuicio, claro, de la transcendencia del secreto desde un plano internacional ${ }^{83}$, como en relación a supuestos concretos de inmunidad jurisdiccional (art. 21.2 LO 6/1985, y LO 16/2015, de 27 de octubre, sobre privilegios e inmunidades de los Estados extranjeros, las Organizaciones Internacionales con sede u oficina en España y las Conferencias y Reuniones internacionales celebradas en España $)^{84}$. Ahora bien, esto último no impide la responsabilidad última del Estado español con relación a la efectiva garantía de los derechos fundamentales con ocasión de actuaciones de servicios de inteligencia de Estados aliados en nuestro territorio (y de los que tenga conocimiento y colabore, de cualquier modo, autoridades españolas), tal como ha evidenciado diversas condenas por el Tribunal Europeo de Derechos Humanos al respecto de actos de servicios extranjeros en distintos Estados europeos por hechos atribuibles a aquéllos ${ }^{85}$;

82 Otra cosa es, claro, la instrumentación que del secreto siempre puedan hacer los servicios de inteligencia ante las actuaciones jurisdiccionales, sin perjuicio, eso sí, de la limitación que tal negativa suponga en las garantías procesales de las partes, y en especial al respecto de la prueba (art. 24.2 CE), según se ha señalado.

83 Por cierto, desde una dimensión exacerbada de la transcendencia de dichas relaciones internacionales en materia de seguridad e inteligencia, vid. la muy polémica Sentencia de la Corte Constitucional italiana 106/2009, de 8 de abril; al respecto, cfr. S. SÁnCHEZ Ferro, «La última jurisprudencia de la Corte Costituzionale italiana en materia de secreto de Estado... cit., pp. 507 y ss. (esp., 511 y ss.).

84 En general, vid. C Gutiérrez Espada, «Sobre la inmunidad de jurisdicción de los estados extranjeros en España, a la luz de la Ley Orgánica 16/2015, de 27 de octubre», Cuadernos de Derecho Transnacional, vol. $8, \mathrm{n}^{\circ} 2,2016$, pp. 5 y ss.

85 Así, p.e., las condenas a: Italia, en Sentencia de 23 de febrero de 2016 (asunto Nasr and Ghali v. Italy, 44883/09); Polonia, en dos Sentencias de 24 de julio de 2014 (Al-Nashiri v. Poland, 28761/11, y Husayn-Abu 
y en base a esto, entonces, la posibilidad del control jurídico de tales actos en España (entendemos) ${ }^{86}$.

De manera más específica ahora al CNI, la Ley 11/2002, recordemos, concreta no sólo su plena sujeción al entero ordenamiento jurídico (art. 2.1), sino su sometimiento al control judicial (art. 2.2). Otra cosa es, claro, los impedimentos que para tal control suponga el referido carácter secreto de buena parte de la actividad, estructura y organización del CNI (art. 5.1, nuevamente), sin perjuicio de cómo: la Audiencia Nacional (Sala de lo Contencioso-Administrativo, Sección $3^{\mathrm{a}}$ ) primero, y en diversos casos sobre nacionalidad (ante su denegación en razón a informes negativos del CNI, mas de carácter secretos), viniera a enervar la intervención del CNI al respecto (p.e., Sentencias de 20 de octubre de 2009, 4 de enero de 2010 y 23 de marzo de 2010) ${ }^{87}$; y el Tribunal Constitucional después, en la ya señalada Sentencia 31/2014, en relación a un supuesto de discriminación (ante un despido de una empleada embarazada y sin que el CNI aportara informe alguno que viniera a justificarlo dado su carácter secreto) acabe superando el silencio del CNI sobre ello (y concediendo el amparo) ${ }^{88}$. Pero además, y en este

Zubaydah-v. Poland, 7511/13); y a Rumanía y Lituania, Sentencias de 31 de mayo de 2018 (respectivamente, y nuevamente, asuntos Al Nashiri v. Romania, 33234/12, y Abu Zubaydab v Lithuania, 46454/11). Sobre tales STEDH, vid. J.M. López Ulla, «El desafío convencional de las entregas extraordinarias», comunicación, en XVII Congreso Asociación de Constitucionalistas de España: Seguridad y libertad en el sistema democrático, Santiago de Compostela, 2019, https://www.acoes.es/congreso-xvii/wp-content/uploads/sites/3/2019/03/El-desaf\%C3\% ADo-convencional-de-las-entregas-extraordinarias.pdf (05/05/2019); y en cuanto a España, y su colaboración en casos similares, vid. N. TORRES UGENA, « «Vuelos secretos» de la CIA complemento a la ilegalidad de Guantánamo», AA.VV. Terrorismo y legalidad internacional, Dykinson, Madrid, 2012, pp. 209 y ss.

86 De modo que la referida protección multinivel de los derechos viene hoy a actuar, incluso, frente a la razón de Estado; cfr. M. REvENGA SÁNCHEZ, «Protección multinivel de los derechos fundamentales y lucha contra el terrorismo a escala europea (a propósito de las listas negras y otras anomalías de la Unión)», RVAP, $\mathrm{n}^{\circ}$ 82 (II), 2008, esp. p. 238.

87 Sobre éstas, vid. J.F. SÁnCHEz BARRILAO, «Inteligencia e inmigración: informes del CNI sobre integración social de solicitantes de nacionalidad española por residencia», AA.VV. Actas del I Congreso Internacional sobre Migraciones en Andalucía, Universidad de Granada / Instituto de Migraciones, Granada, 2011, pp. 1691 y ss.

88 FJ n $n^{\circ}$ 5: «Una vez sentada la existencia de un panorama indiciario de discriminación, correspondía a la Administración probar que la decisión del cese de la recurrente obedeció a razones objetivas y ajenas por completo a cualquier ánimo discriminatorio, alegando que el cese se produjo por razón de la falta de idoneidad de la recurrente reflejada en diversos aspectos negativos que pusieron de manifiesto determinados informes que, sin embargo, no se aportan por la Administración por estar clasificados como secretos. / En efecto, la Administración utilizó un formulario de cese y sólo fundó mínimamente su decisión al resolver el recurso de reposición interpuesto por la demandante por Resolución de fecha 27 de octubre de 2010, argumentando que concurría el supuesto de inidoneidad que recoge el art 18 d) del estatuto del personal del centro. En dicha resolución no se hacía referencia a ningún elemento en concreto que determinara una valoración negativa sobre la demandante, si bien existe un informe previo de la Asesoría Jurídica de fecha 1 de octubre de 2010 (folios 64-66) donde se opone la existencia de dos informes, de fechas 16 de diciembre de 2009 y 15 de julio de 2010 , de la Dirección de Apoyo a la Inteligencia, que contenían aspectos desfavorables al desempeño de la recurrente. / Esos informes desfavorables son los que justificaron la decisión de cese, según mantuvo la Administración en el procedimiento judicial de derechos fundamentales, si bien en ningún momento llegó a aportarlos al procedimiento, al no incluirlos en el expediente administrativo ni tampoco remitirlos cuando fue requerida al efecto por el Juzgado Central de lo Contencioso-Administrativo número 12, con fundamento en que se trataba de 
último caso, aportando el Tribunal Constitucional una interesante respuesta a la garantía del secreto y el necesario control de la actuación jurisdiccional del CNI con ocasión de derechos fundamentales, al hacer referencia a que la Administración, «preservando la información material cubierta por la legislación de secretos oficiales, podía haber concretado motivadamente una suficiente explicación que permitiera conocer aquellos hechos o aspectos negativos del desempeño de sus funciones que fueran relevantes para que no se integrara a la demandante como personal estatutario permanente y en todo caso, fueran susceptibles del necesario control judicial, todo ello con las debidas cautelas para no infringir el carácter secreto de los documentos y la necesaria preservación de la seguridad nacional» (FJ núm. 6, in fine); es decir, el deber de la Administración de distinguir entre aquella información que sea realmente relevante para la seguridad de la que no lo sea, a fin de una efectiva tutela judicial y control jurisdiccional en todo lo posible, en vez de escudarse simplemente en el secreto (nuevamente, arts. 24 y 106.1 CE). $\mathrm{Y}$ de este modo, que junto a la consideración restrictiva que del secreto se mantiene de manera general al respecto del principio constitucional de publicidad, quepa una reconsideración aún más restrictiva cuando de afectación de derechos fundamentales se trate. Con todo, claro, es que sean los tribunales ordinarios a los que, de acuerdo al principio de exclusividad jurisdiccional (art. 117.3 CE), les corresponda decidir hasta qué punto elementos relativos a la inteligencia (y en particular al CNI) y secretos son pertinentes conocer para un adecuado desarrollo de su función jurisdiccional y al respecto del derecho a la prueba (art. 24.2 CE, nuevamente); y ello por más que una parte del proceso haya solicitado tales elementos como prueba (siempre y fundando oportunamente su denegación), o que en caso contrario se inste entonces y judicialmente al Gobierno a su desclasificación (según se ha adelantado) ${ }^{89}$, pudiéndose ser recurrida incluso su denegación conforme a las referidas Sentencias del Tribunal Supremo de 4 de abril de $1997^{90}$.

informes declarados secretos, ante lo cual el Juzgado Central se aquietó y desestimó la solicitud de la demandante que en el trámite de prueba solicitó la aportación de los citados informes al entender dicha proposición de prueba como impertinente. Finalmente, la Sentencia de apelación tampoco atiende la petición de la recurrente de que se acuerde lo necesario para que se aporten los informes. / En definitiva, no existe ningún elemento que desvirtúe los elementos indiciarios de discriminación a los que hemos hecho referencia, no habiéndose aportado los informes negativos citados en el informe de la Asesoría Jurídica del Centro Nacional de Inteligencia de fecha 16 de diciembre de 2009 y 15 de julio de 2010, al estar clasificados como secretos».

89 Así, Sentencia de 14 de diciembre de 1995, recaída en el conflicto de jurisdicción n ${ }^{\circ}$ 10/1995-T, planteado entre el Ministerio de Defensa y el Juzgado de Instrucción n ${ }^{\circ} 5$ de la Audiencia Nacional. Sobre ésta, vid. L.M. DíEz-PiCAZo, «El secreto de Estado en el proceso penal: a propósito de la Sentencia del Tribunal de Conflictos de Jurisdicción de 14 de diciembre de 1995», Sobre secretos oficiales... cit., pp. 21 y ss., y 51 y ss.; y de manera crítica, B. LozAno, La desclasificación de los secretos de Estado, Civitas, Madrid, 1998. También, R. Lasaga SANZ, «Secretos de Estado y Constitución: Fundamentos y técnicas de control», RVAP, n ${ }^{\circ} 54$, 1999, pp. 92-96; y J.J. DíEz SÁNCHEZ, op. cit., pp. 238-240. Por cierto, acerca de la efectiva desclasificación por el Gobierno de información y documentación a instancia de los jueces (al menos, ya, en 9 ocasiones), vid. https://www.moncloa.com/gobierno-secretos-villarejo/ (30/04/2019).

90 Cfr. la referida STS, Sala Segunda de lo Penal, 1094/2010 (FD n ${ }^{\circ}$ 2.C). No en vano, y a la vista del asimismo referido art. 2.a L 29/1998, es que la propia indefensión pueda considerarse, en tanto que 
Otra cosa, claro, es qué acontezca al tiempo con relación a una justicia en un plazo razonable (otra vez art. $24.2 \mathrm{CE})^{91}$.

Con todo, ¿cómo puede recurrirse un acto secreto, y por tanto tendencialmente destinado a su desconocimiento? A la vista de la plena sujeción de toda actuación pública a la Constitución y al resto del ordenamiento jurídico (art. 9.1 y 3 CE), así como a su ulterior control jurisdiccional (art. 106.1 CE), y en particular al respecto del CNI (art. 2.1 y 2 L 11/2002, otra vez), no se puede impedir que el secreto limite el efectivo acceso a la tutela jurisdiccional de derechos e intereses legítimos (art. 24.1 CE), de modo que, en caso de conocerse un acto secreto, éste puede ser plenamente recurrido (nuevamente, art. 106.1 CE) ${ }^{92}$ sin perjuicio de que: de un lado, a nivel judicial se proceda a adoptar las medidas necesarias a fin de garantizar la oportuna reserva respecto a aquellos elementos declarados secretos y susceptibles de afectar, de manera efectiva, a la seguridad (otra vez arts. 120.1 CE, y 232.3, 234.2, 476.1.f, 497.f y 542.3 LO 6/1985) 93; y de otro, y conforme lo señalado más arriba, que el grado del control jurisdiccional dependa tanto de la naturaleza de los derechos afectos de garantía judicial, como de la incidencia del acto con relación a la seguridad y a la defensa (nuevamente, SSTS, Sala $3^{\mathrm{a}}$, de 4 de abril de 1997). Y para ello, y como plantea Melero Alonso, a partir de tres parámetros de control: la afectación, o no, de la información clasificada a la seguridad y defensa del Estado; la probabilidad de que su desclasificación dañe o ponga en riesgo efectivo la seguridad y la defensa; y, con todo, la ponderación de lo anterior con los derechos (o intereses) con los que entre en conflicto $^{94}$. Por ello es por lo que resulta oportuno plantearse la posibilidad legal de que, finalmente, la mera negativa de la Administración de aportar a un proceso una información secreta pueda ser resuelta directamente jurisdiccionalmente, en vez de tener que solicitar previamente la referida desclasificación al Gobierno (y su ulterior recurso contencioso $)^{95}$; mas ello, no obstante, sin perjuicio de la limitación de conocimiento en cuanto a las partes procesales de tales secretos hasta tanto se resuelva favorablemente su desclasificación ${ }^{96}$. Otra cosa es, y conforme se

vulneración de derecho fundamental, como causa del control jurisdiccional; en tal sentido, Á.L. Alonso DE Antonio, «La Ley de secretos oficiales... cit., p. 225-226.

$91 \mathrm{Al}$ respecto, y desde la jurisprudencia del TEDH, vid. C. MiLIONE, El derecho a la tutela judicial efectiva en la jurisprudencia del Tribunal Europeo de Derechos Humanos, Tirant lo Blanch, Valencia, 2015, pp. 135 y ss.

92 Así, M. Revenga SánChez, «Razonamiento judicial, seguridad nacional y secreto de estado», REDC, $\mathrm{n}^{\circ} 53,1998$, p. 61.

93 En tal línea, STEDH, 15 de noviembre de 1996, asunto Chahal v. Reino Unido; y al respecto de la misma, M. Revenga SÁNCHEZ, op. cit., pp. 68 y ss.

94 E. Melero Alonso, «El control judicial de los secretos de Estado en España. A propósito de las exportaciones de armamento», Opinión Jurídica, vol. 7, n 14, 2008, pp. 15 y ss.; asimismo, de interés, J.J. DíEz SÁnCHEZ, op. cit., pp. 128-130.

95 En tal sentido, cfr. J.J. Torres Ventosa, «La regulación legal de los secretos oficiales», Anuario de la Facultad de Derecho (Universidad de Extremadura), n 16,1998 , pp. 357 y ss.

96 Y así, a modo de auténtica prueba secreta, y como problema distinto a la prueba de información considerada secreta; al respecto de lo primero, y al hilo de la saga de sentencias del TJUE en el asunto Kadi, vid. 
abordará al final del trabajo, si la anterior facultad de control jurisdiccional del secreto debiera (en su caso) concentrarse en un determinado órgano jurisdiccional (por lo demás, el Tribunal Supremo).

\section{INTELIGENCIA Y CONTROL JUDICIAL PREVIO}

En un paso más, la Ley 11/2002 previó también y expresamente el control judicial previo, si bien «en la forma prevista en la Ley Orgánica reguladora del control judicial previo del Centro Nacional de Inteligencia, complementaria de la presente Ley» (arts. 2.1 y 12) ${ }^{97}$. Ello, en principio, no es sino una manifestación genérica de la configuración constitucional de la atribución legal de funciones no jurisdiccionales de los jueces en garantía de derechos (art. 117.4 CE), y de manera más concreta de la exigencia constitucional de autorización judicial previa para entradas en domicilios e intervenciones telefónicas (art. 18.2 y 3 $\mathrm{CE})^{98}$, si bien con la particular singularidad de garantía y verificación de que tales actuaciones intrusivas del CNI en la esfera de los derechos de las personas tengan por exclusiva finalidad aquéllas que son invocadas ( $\mathrm{y}$ en cuanto que estrictamente relativas a la seguridad), así como que su materialización se lleven a cabo en su grado mínimo e imprescindible ${ }^{99}$. Tal previsión se tramitó y aprobó de manera paralela a la Ley 11/2002, a través de la Ley Orgánica 2/2002, de 6 de mayo ${ }^{100}$, y limitándose a establecer el control judicial previo de las actividades del CNI que afecten sólo a los derechos fundamentales relativos a la inviolabilidad del domicilio y al secreto de las comunicaciones. Sin embargo, aunque tales derechos fundamentales pueden considerarse como los más afectados tradicionalmente en relación a investigaciones relativas a personas (así, art. $5.5 \mathrm{~L}$ 11/2002), no cabe excluir la potencial afectación de otros derechos fundamentales, y por tanto el que dicho control previo judicial se hubiera debido extender

M. REvenga SÁNCHEZ, «El proceso debido y las pruebas de carácter secreto ante el Tribunal de Justicia de la Unión Europea: ¿un dilema irresoluble?», AA.VV. La Constitución y sus garantías. A 100 años de la Constitución de Querétaro de 1917 (Memoria del XI Encuentro Iberoamericano y VIII Congreso Mexicano de Derecho Procesal Constitucional), Instituto de Estudios Constitucionales del Estado de Querétaro/UNAM/Instituto de Investigaciones Jurídicas, México, 2017, pp. 765 y ss.

97 Un control que, aunque limitado (y con no pocas cuestiones abiertas, según se viene luego a mostrar), supuso un importante paso respecto a la situación anterior y los abusos cometidos; en tal sentido $c f r$, p.e., A. Ава Catoira, «El secreto de Estado y los servicios de inteligencia... cit., pp. 143 y ss. y esp. 150.

98 Con carácter general, vid. J.F. SÁNCHEZ BARRILAO, Las funciones no jurisdiccionales de los jueces en garantía de derechos, Civitas, Madrid, 2002, esp. Cap. IV.

99 Cfr. J.M. UGARTE, «Control», AA.VV. Conceptos fundamentales de inteligencia ... cit., p. 76.

100 Al respecto: M.C. PÉrez Villalobos, Derechos fundamentales y servicios de inteligencia, Grupo Editorial Universitario, Granada. 2002; F.L. PASCUAL SARriá, «El control judicial a la interceptación de las comunicaciones: especial referencia al control judicial previo a las intervenciones del Centro Nacional de Inteligencia», REDM, ñ 89, 2007, pp. 163 y ss.; y J.L. GONZÁLEZ CuSSAC, «Intromisión en la intimidad y servicios de inteligencia», Revista Penal México, n 3, 2012, pp. 159 y ss. Y a nivel jurisprudencial, la referida STS, Sala de lo Penal, 1094/2010 (FD n 2.A). 
en garantía de éstos. Por otra parte, tal previsión legal responde al requerimiento constitucional de garantizar el secreto de las comunicaciones y la inviolabilidad del domicilio ante la necesidad de su limitación con ocasión de una investigación del CNI necesaria «para la seguridad nacional, la seguridad pública, el bienestar económico del país, la defensa del orden y la prevención del delito, la protección de la salud o de la moral, o la protección de los derechos y las libertades de los demás» ${ }^{101}$. Y de este modo que se esté ante un control judicial previo de concretas actividades del CNI que supongan limitación de derechos fundamentales, en pos de garantizar la debida necesidad, razonabilidad y proporcionalidad de dichas medidas en relación a tales derechos, según valoración judicial conforme a las circunstancias del caso.

A estos efectos, cuando sea necesaria la adopción de medidas por el CNI «para el cumplimiento de sus funciones» y éstas afecten a la inviolabilidad del domicilio y al secreto de las comunicaciones, el Director de mismo deberá solicitar al Magistrado del Tribunal Supremo competente la referida autorización (art. único.1 LO 2/2002) ${ }^{102}$. Tal solicitud se hará por escrito (art. único.2 LO 2/2002) ${ }^{103}$, debiendo dicho Magistrado acordar, «mediante resolución motivada en el plazo improrrogable de setenta y dos horas, la concesión o no de la autorización solicitada» (art. único.3 LO 2/2002), lo que supone, por parte del Magistrado competente, un juicio de la justificación y la proporcionalidad de la medida solicitada, a fin de la efectiva garantía de los referidos derechos. Por otra parte, y al amparo del carácter secreto de las actuaciones del CNI (en general, el varias veces referido art. 5.1 L 11/2002), el «Magistrado dispondrá lo procedente para salvaguardar la reserva de sus actuaciones, que tendrán la clasificación de secreto» (art. único.3, in fine, LO 2/2002); y a fin de salvaguardar ahora los derechos afectados por las anteriores medidas, que el Director del CNI ordene «la inmediata destrucción del material relativo a todas aquellas informaciones que, obtenidas mediante la autorización prevista en este artículo, no guarden relación con el objeto o fines de la misma» (art. único.4 LO 2/2002).

Son varias (y de notable interés) las cuestiones que se suscitan a la luz de la anterior normativa. En principio, resulta innegable la necesaria sujeción del CNI

101 Exposición de motivos de la LO 2/2002; y ello, adviértase, incorporándose como motivos de limitación de derecho el grueso de límites expresamente previstos por el CEDH (art. 8.2).

$102 \mathrm{Al}$ respecto, la LO 2/2002 (disp. adic. única) determinaba la forma de nombramiento tal Magistrado, reformando a dicho fin arts. 125.5, 127.4, 135 y 342.bis LO 6/1985. No obstante, al tiempo, los arts. 125.5, 127.4 y 135 resultarían derogados por LO 4/2013, de 28 de junio, de reforma del CGPJ, y viniendo además a redactar un nuevo art. 598.9 LO 6/1985.

103 La cual deberá de contener: las específicas «medidas que se solicitan»; los hechos «en que se apoya la solicitud, fines que la motivan y razones que aconsejan la adopción de las medidas solicitadas»; la identificación «de la persona o personas afectadas por las medidas, si fueren conocidas, y designación del lugar donde hayan de practicarse»; y la duración de las medidas, «que no podrá exceder de veinticuatro horas en el caso de afección a la inviolabilidad del domicilio y tres meses para la intervención o interceptación de las comunicaciones postales, telegráficas, telefónicas o de cualquier otra índole», si bien ambos plazos son prorrogables por sucesivos períodos iguales en caso de necesidad. 
a la Constitución y al resto del ordenamiento jurídico, y en especial respecto a los derechos fundamentales (art. 53.1 CE); pero ello, al igual que acontece con cualquier otro órgano con atribuciones en inteligencia (como el CIFAS o el CITCO). Siendo destacable que se haya establecido específicamente un procedimiento judicial en garantía previa de derechos susceptibles de limitación por el CNI en su actuación, a la par que garante del secreto propio con el que ha de contar la actuación de éste, no se entiende, en cambio, que tal regulación no se hubiera extendido a otras actuaciones de la inteligencia pública distinta del CNI (nuevamente el CIFAS o el CITCO) cuando la tensión resuelta por la Ley Orgánica 2/2002 es la misma en dichos casos (defensa/seguridad, secreto, derechos). Por tanto, y para estos supuestos diversos al CNI se habrá de estar al régimen ordinario de autorización judicial al respecto de la limitación de la inviolabilidad del domicilio y del secreto de las comunicaciones (del que luego vendremos a hablar $)^{104}$; y ello, evidentemente, con toda la problemática que supone la irrupción del secreto al respecto de la intervención judicial ${ }^{105}$.

Por otra parte, hubiera sido también oportuno extender dicho control previo judicial a otros derechos fundamentales, asimismo susceptibles de limitación con ocasión de investigaciones de seguridad sobre personas por parte del CNI. En tal sentido, y por ejemplo al respecto de la ciberinteligencia hoy, y de cómo, de un lado, la intimidad personal (art. 18.1 CE) se extiende a ordenadores y a otros aparatos informáticos en los que se contengan datos personales (STC 173/2011, de 7 de noviembre de 2011, FJ núm. 3), y de otro que la limitación pública de los mismos (en cuanto que entrada o intromisión por los poderes públicos) requiere de autorización judicial previa (nuevamente STC 173/2011, FJ núm. 2) ) $^{106}$. En tal

$104 \mathrm{Y}$ en especial con relación a la inteligencia policial y al régimen previsto para la limitación de derechos fundamentales por la LECr (al que seguidamente nos vamos a referir); régimen que entendemos supletorio para el caso de la inteligencia militar, a la vista de disp. adicional primera LO 2/1989, de 13 de abril, Procesal Militar (sin perjuicio de su Tít. II, Cap. VI). Con todo, adviértase cómo en ambos casos (pero particularmente al respecto de la inteligencia militar y sus fines) el ámbito de aplicación de dicha normativa procesal queda delimitada al marco jurisdiccional-criminal (bastante más limitado para la militar, conforme LO 4/1987, de 15 de julio, de la Competencia y Organización de la Jurisdicción Militar), lo que obviamente puede no cubrir el abanico de actuaciones de la inteligencia policial y militar (especialmente en este último supuesto, insistimos). En cuanto a otros casos de limitaciones de derechos fundamentales por los poderes públicos al hilo de otras manifestaciones de la comunidad de inteligencia, se habría de estar a regímenes específicos, como p.e. acontece a: intervenciones en orden a la salud pública (así, epidemias y pandemias conforme Estrategia de Seguridad Nacional de 2017), según arts. 1, 2 y 3 LO 3/1986, de 14 de abril, de Medidas Especiales en Materia de Salud Pública, y 8.6 L 29/1998; o en materia de transferencia internacional de datos, art. 122.ter asimismo L 29/1998.

105 Desde esta consideración crítica, es que F.L. PASCUAL SARriá, y en el caso del CIFAS, entienda que éste deba activar el referido mecanismo de control judicial previo mediante su comunicación al Director del CNI a tal fin («El control judicial a la interceptación de las comunicaciones... cit., p. 193).

106 Una autorización judicial en la que el Juez debe garantizar su legitimidad, en tanto que justificada, proporcional y razonable, de la limitación propuesta en atención a las razones de seguridad y circunstancias alegadas en el supuesto particular. En esta perspectiva, vid. J.L. GonZÁLEZ CussaC, «Intromisión en la intimidad y CNI. Crítica al modelo español de control judicial previo», Inteligencia y Seguridad, $\mathrm{n}^{\circ}$ 15, 2014, pp. 151 y ss. 
sentido, además, recuérdese como la Ley ha extendido de manera ordinaria y expresamente la autorización judicial en las investigaciones criminales con relación a la interceptación de comunicaciones telemáticas, la captación y grabación de comunicaciones orales mediante la utilización de dispositivos electrónicos, la utilización de dispositivos técnicos de seguimiento, localización y captación de la imagen, el registro de dispositivos de almacenamiento masivo de información y los registros remotos sobre equipos informáticos conforme a los artículos 588.bis.a y siguientes de Ley de Enjuiciamiento Criminal según Ley Orgánica 13/2015, de 5 de octubre (de modificación de la Ley de Enjuiciamiento Criminal para el fortalecimiento de las garantías procesales y la regulación de las medidas de investigación tecnológica ${ }^{107}$; y ello, por más que, aun no siendo lo mismo tales actuaciones en relación a una investigación criminal que la llevada a cabo por el $\mathrm{CNI}^{108}$, sí que, efectivamente, suponga actuaciones asimilables ${ }^{109}$. No obstante,

$107 \mathrm{Al}$ respecto de ésta, vid., de un lado: C. Rodríguez RUBIO, «La injerencia en el derecho al secreto de las comunicaciones a través de la regulación de las medidas de investigación tecnológica», Revista Europea de Derechos Fundamentales, n ${ }^{\circ}$ 28, 2015, pp. 267 y ss., en especial pp. 278 y ss.; e I. LópeZ-BARAJAS PEREA, «Garantías constitucionales en la investigación tecnológica del delito: previsión legal y calidad de la ley», RDP, n $\mathrm{n}^{\circ}$ 98, 2017, pp. 91 y ss. También, acerca del seguimiento de una persona mediante GPS por motivo de la seguridad nacional, la seguridad pública y el derecho de las víctimas y la prevención de delitos, STEDH, de 2 de septiembre de 2010, en el asunto Uzun v. Alemania; y sobre la utilización de agentes encubiertos virtuales o informáticos en base al art. 282.bis LECr (asimismo conforme LO 13/2015), en cuanto que, al poder afectar a derechos fundamentales, se requiere de autorización judicial, STS, Sala de lo Penal, Sec. 1, 345/2019, de 7 de febrero.

108 STS 1094/2010 (FD n 2.A, nuevamente): «La singularidad deriva, claro es, del hecho de que el Magistrado autorizante ha de verificar una ponderación de bienes jurídicos que no se identifican con los que son valorados en el seno de un proceso penal. La posición institucional del Magistrado llamado al control previo no está exenta de dificultades. De una parte, por cuanto que los parámetros a partir de los cuales ha de resolver la petición cursada por el Director del CNI, instando el sacrificio de derechos fundamentales, no son los ponderados con carácter general cuando se trata de la investigación de un hecho delictivo. Detectar cuándo una actividad determinada puede implicar un riesgo para los intereses económicos, industriales o comerciales de España o cuándo encierra una amenaza al bienestar de la población, no es cuestión sencilla. De hecho, algunos de esos bienes — no todos los que se mencionan en el art. 4 de la Ley 11/2002 — escapan a una dimensión estrictamente jurídica, habiendo generado dudas doctrinales acerca del distanciamiento de una genuina justificación material en el momento de autorizar el acto de injerencia».

109 No en vano el TS, en su referida STS 1094/2010 (FFDD núms. 2.A y ss.) no termina de entender adecuadamente la intervención judicial previa en garantía de derechos (fundamentales), por más que, certeramente, la infiere del art. 117.4 CE; y es que dichas funciones no son actividad jurisdiccional (ni en el caso de las llevadas a cabo en una instrucción penal), y por tanto no le son trasladables las garantías procesales ordinarias del art. $24 \mathrm{CE}$. El ámbito de actuaciones judiciales que abre dicho precepto constitucional es realmente muy amplio (art. 117.4), dando lugar a una diversidad de regímenes jurídicos distintos. Por supuesto que no es igual una investigación criminal que la labor de inteligencia, como tampoco lo es una restricción de la libertad física por motivos penales que en relación a una persona por causa de salud psíquica o pública. Pero ello no impide que en ausencia de normas legales que desarrollen específicamente cada una de las intervenciones judiciales en garantía de un derecho quepa cierta aplicación analógica de un régimen a otro; y esto, en especial, a fin de evitar actuaciones públicas capaces de afectar derechos fundamentales y libertades sin adecuadas y oportunas normas legales en desarrollo de la reserva de ley del art. 53.1 CE. Sobre tal alcance amplio y diverso de las intervenciones judiciales en garantía de derechos (art. 117.4 CE), cfr. J.F. SÁNCHEZ BARRILAO: «XI Intervención social. 1. Restricciones en orden a la protección de la salud: restricciones de la libertad por causa de enfermedad infecto-contagiosa e internamientos en establecimientos psiquiátricos», AA.VV. El 
cierta ampliación sustantiva de derechos, y del régimen de limitación y autorización judicial de los mismos, cabe advertir expresamente al tiempo; así sucede al hilo de la Ley 25/2007, de 18 de octubre, de conservación de datos relativos a las comunicaciones electrónicas y a las redes públicas de comunicaciones (art. 18.4 $\mathrm{CE}$, ahora $)^{110}$, al facultar el acceso a tales datos al personal del CNI «en el curso de las investigaciones de seguridad sobre personas o entidades» conforme a lo previsto en la referida Ley Orgánica 2/2002 (art. 6.d.c), mas, entendemos, de acuerdo al régimen previsto por la propia Ley 25/2007 (en especial, art. 1 y Cap. II).

Otra cuestión de carácter general es la imposibilidad, a veces, de delimitar estricta e indiciariamente los sujetos potenciales de medidas limitativas de derechos fundamentales y libertades al respecto de actuaciones de los servicios de inteligencia cuando éstos actúan con carácter preventivo a fin de evitar la materialización de graves amenazas, de manera que la atención judicial autorizando dicha limitación se ha de centrar en un riguroso juicio de proporcionalidad a fin de evitar una indeterminación arbitraria de la medida ${ }^{111}$. En tal sentido, particular relevancia alcanzan hoy los llamados controles cibernéticos colectivos e inespecíficos. Si bien no caben, en principio, el uso de instrumentos de seguimiento indiferenciado y en masa (o a gran escala) de contenidos en red (ni directa, ni indirectamente mediante la transferencia ahora de datos por particulares a los servicios de inteligencia) ${ }^{112}$, es que a la vista de la jurisprudencia del Tribunal Europeo de Derechos Humanos se abra sin embargo la posibilidad a dichos controles

principio constitucional de intervención indiciaria, Grupo Editorial Universitario, Granada, 2000, pp. 133 y ss.; nuevamente, Las funciones no jurisdiccionales de los jueces en garantía de derechos... cit., Cap. IV; y, especialmente, «Régimen constitucional del internamiento involuntario y urgente por trastorno mental», RDP, $\mathrm{n}^{\circ} 87,2013$, pp. 179 y ss.

110 Al hilo de la L 9/2014, de 9 de mayo, General de Telecomunicaciones (disp. final $4^{\mathrm{a}} 1$ ).

111 De interés, M.C. PÉrez Villalobos, Derechos fundamentales y servicios de inteligencia... cit., pp. 81-83. Cuestión distinta es que las circunstancias sí quepan admitir dicha delimitación, de modo que el juez deba tenerlo en cuenta, sin perjuicio de que realizada la medida se advierta ulteriormente la desconexión indiciaria del sujeto al respecto de la misma (debiéndose levantar entonces cualquier medida adoptada sobre él). Sin duda, la gran dificultad del control en garantía judicial previa de derechos por el juez con ocasión de la seguridad y la inteligencia reside hoy en la aguda tensión que alcanzan los binomios riesgo-amenaza y prevención-necesidad; desde una perspectiva crítica, cfr. A. BusH, «La arquitectura cambiante del estado de seguridad nacional», AA.VV. Transformaciones del Estado contemporáneo, R. Cotarelo (trad.), Tirant lo Blanch, Valencia, 2017, pp. 463-464.

112 Así, SSTJUE: de 24 de noviembre de 2011, asunto C-70/10 [sobre ésta, vid. G. GonzÁlez FusTER, «Equilibrio entre propiedad intelectual y protección de datos: el peso oscilante de un nuevo derecho», IDP (revista de Internet, derecho y política / revista d'Internet, dret i política), $\mathrm{n}^{\circ} 14$, 2012, pp. 34 y ss., https://idp. uoc.edu/articles/abstract/10.7238/idp.v0i14.1547/ (26/08/2018)]; de 8 de abril de 2014, asuntos acumulados C-293/12 y C-594/12 [p.e.: V. Guasch Portas y J.R. Soler Fuensanta, «El interés legítimo en la protección de datos», Revista de Derecho UNED, n 16, 2015, pp. 417 y ss.; y Rosario SERra CristóbaL, «La opinión pública ante la vigilancia masiva de datos. El difícil equilibrio entre acceso a la información y seguridad nacional», RDP, no 92, 2015, pp. 106-108]; y de 6 de octubre de 2015, asunto C-362/14 [E. URía Gavilán, «Tribunal de Justicia de la Unión Europea - Derechos fundamentales versus vigilancia masiva. Comentario a la sentencia del Tribunal de Justicia (Gran Sala) de 6 de octubre de 2015 en el asunto C-362/14 Schrems», Revista de Derecho Comunitario Europeo, nº 53, 2016, pp. 261 y ss.; también de interés, vid. J.F. LópEZ AGUILAR, «La protección de datos personales en la más reciente jurisprudencia del TJUE: Los derechos de la 
cibernéticos colectivos, mas no arbitrarios (eso sí) ${ }^{113}$, en cuanto que (y al margen, claro, de la ya referida reserva de ley al respecto $)^{114}$ con debidas garantías a fin de impedir el abuso por los poderes con relación a una indeterminación masiva de personas objeto de monitorización: en tanto que imposible de delimitar de manera estricta e indiciaria los sujetos potenciales de tales medidas; procurándose evitar que se alcance fácilmente a sujetos que en nada tengan que ver con las actividades objeto de control; exigiéndose una efectiva evaluación de la necesidad de la adopción de dicha intervención colectiva e inespecífica; estableciéndose concretos y apropiados mecanismos de control para tales medidas; y conforme a una adecuación del filtrado, de la búsqueda y de la selección de la información a interceptar o retener por los propios servicios secretos, como por proveedores de servicios de

CDFUE como parámetro de validez del Derecho europeo, y su impacto en la relación transatlántica

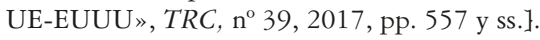

113 Casos: Klass y otros v. Germany, de 6 de septiembre de 1978, sobre monitorización por los servicios secretos de correspondencia y comunicaciones telefónicas sin obligación de comunicar a los afectados las medidas adoptadas en caso de terrorismo ( $\sin$ condena, ante la excepcionalidad de las condiciones requeridas al respecto por el legislador); Weber y Saravia v. Germany, de 29 de junio de 2006, asimismo acerca de la monotorización de comunicaciones (tampoco hay condena, al existir adecuadas y efectivas garantías frente a posibles abusos del Estado); Liberty y otros $v$. the United Kingdom, de 1 de julio de 2008, sobre interceptación de comunicaciones e información confidencial (ahora sí con condena por abuso de poder, ante la inexistencia de suficientes criterios de actuación, y falta de destrucción ulterior del material interferido); y Kennedy v the United Kingdom, de 18 de mayo de 2010, nuevamente en relación con la intercepción de comunicaciones (en este caso no hay condena, a la vista de la existencia de un código de buenas prácticas en las que se determina con suficiente claridad el procedimiento, la forma y los casos en los que autorizarse dichas interceptaciones) [sobre éstas, vid. E. SAlAmANCA AgUADO, «El respeto a la vida privada y a la protección de datos personales en el contexto de la vigilancia masiva de comunicaciones», Revista del Instituto Español de Estudios Estratégicos, $\mathrm{n}^{\circ}$ 4, 2014, http://revista.ieee.es/index.php/ieee/article/ view/137/215 (22/08/2018)]. Asimismo, al tiempo, cfr. las SSTEDH Roman Zakharov v. Russia, de 4 de diciembre de 2015, al respecto de la interceptación secreta de teléfonos móviles (con condena ante la falta de suficientes garantías acerca de tales interceptaciones y el riesgo de abuso; asimismo vid. Szabó y Vissy v. Hungría (de 12 de enero de 2016), y Akblyustin v. Russia, Zubkov y otros v. Russia, Moskalev v. Russia y Konstantin Moskalev v. Russia, todos de 7 de noviembre de 2017); Centrum För Rättvisa v. Sweden, de 19 de junio de 2018, sobre la interceptación de comunicaciones al servicio de inteligencias extranjeras (mas sin condena, al considerarse suficientes y adecuadas las garantías legalmente previstas en cuanto a la adopción de las medidas, como a sus límites y control, confinándose así la arbitrariedad estatal y su potencial amenaza y abuso); y muy especialmente los asuntos Szabó y Vissy v. Hungary, de 12 de enero de 2016 (acerca de medidas intrusivas por servicios secretos a fin de la seguridad nacional), y Big Brother Watch y otros $v$. the United Kingdom, de 13 de septiembre de 2018 (sobre la interceptación de comunicaciones en masa, la cesión de información por los servicios de inteligencia con los de otros países y la obtención de datos a través de proveedores de servicio), pues, aun declarando el TEDH la existencia en ambos casos de violación de derechos y libertades [vid:: M.Á. Iglesias VÁzQUEZ, «Ponderando derechos fundamentales. El Tribunal Europeo de Derechos Humanos: el derecho a la privacidad y la seguridad nacional», comunicación, XVII Congreso Asociación de Constitucionalistas de España: Seguridad y libertad en el sistema democrático, Santiago de Compostela, 2019, pp. 15-17/23, https:/www.acoes.es/congreso-xvii/wp-content/uploads/sites/3/2019/03/ Mar\%C3\%ADa-del-\%C3\%81ngel-Iglesias-V\%C3\%A1zquez.pdf(05/05/2019); y M. Arenas Ramiro, «Los sistemas de vigilancia masiva de comunicaciones. A propósito de la STEDH Big Brother Watch, de 13 de septiembre de 2018», Diario La Ley, 2019], admite la posibilidad de monitorizar informáticamente comunicaciones colectivas e inespecíficas a fin de evitar ataques terroristas en razón al grado de amenaza que hoy alcanza el terrorismo global.

114 Cfr. R. Serra Cristóbal, op. cit., pp. 100-102. 
comunicación, portadores de Internet o prestadores de meros servicios en Internet para el caso de cesión de datos por éstos a aquéllos (pero requiriéndose entonces, además, una pertinente supervisión sobre ellos a tales efectos) ${ }^{115}$.

Al margen de lo señalado más arriba, es que quepa excepcionalmente la intromisión pública en derechos fundamentales sin autorización judicial cuando: concurran motivos justificados para la intervención inmediata, por su extraordinaria urgencia y necesidad; la intervención sea siempre conforme a los principios de proporcionalidad y razonabilidad, y en atención a un juicio previo a su materialización; y sin perjuicio, eso sí, de un potencial y efectivo control judicial ex post, en su caso (otra vez STC 173/2011, FJ núm. 2) ${ }^{116}$. Naturalmente el juicio deberá ser especialmente intenso, ante el riesgo abstracto que las intromisiones sin control judicial previo generan no sólo al respecto de los derechos fundamentales de las personas, en concreto, sino sobre el mismo Estado de Derecho, en general; y en dicho juicio, con singular referencia a la urgencia en razón al tiempo necesario que habría de llevarse o necesitar el control judicial previo ante las extraordinarias circunstancias de los casos y los fines a asegurar ${ }^{117}$. Otra cosa es quién pueda en tales supuestos tomar tal decisión (entendemos que sólo podría hacerlo el Director del CNI, en cuanto que máximo responsable del mismo, a la par que competente para pedir la intervención del control previo a realizar por el Magistrado del TS), y que, en todo caso, dicha decisión debiera someterse a control judicial (aun a posteriori) lo más pronto posible (en especial, cuando de medidas restrictivas que se hayan de mantener en el tiempo); con todo, adviértase cómo la Ley Orgánica 2/2002 prevé expresamente supuestos de urgencia, en los que, debidamente motivados por el Director del CNI, se podrá requerir la decisión judicial en un plazo máximo de 24 horas (art. único.3), lo que lleva entonces a que sólo en casos de extremísima urgencia quepa intervenciones sin autorización previa (por cuanto que tan breve plazo haría inútil la intervención en el derecho al respecto de los fines que la justificase $)^{118}$.

115 En esta línea, A. González Monje, «Amenazas a la seguridad y privacidad: la dificultad del equilibrio perfecto», Revista Europea de Derechos Fundamentales, n 29, 2017, pp. 267 y ss., y en especial 292293. También, y en el ámbito de la Unión Europea, vid. FRA (European Union Agency for Fundamental Rights), «Surveillance by intelligence services: fundamental rights safeguards and remedies in the EU (Volume I: Member States'legal frameworks)», 2015, http://fra.europa.eu/en/publication/2015/surveillance-intelligence-services (17/09/2018).

116 Así, y a nivel legal, vid. arts. 579.3, 588.ter.d.3, 588.quinquies.b. 4 y 588.sexies.c.3 y 4 LECr. No obstante, la apreciación de la urgencia en el caso concreto resuelto por la referida STC 173/2011 vendría a verse desautorizada por la ulterior STEDH de 30 de mayo de 2017, en el asunto Trabajo Rueda v. España; sobre esta STEDH, vid. J. Ocón, «Derecho a la intimidad y registro de dispositivos informáticos: a propósito del asunto Trabajo Rueda c. España», REDC, nº 113, 2018, pp. 327 y ss.

$117 \mathrm{Al}$ respecto, vid. (si bien en relación con la labor policial en materia criminal) nuevamente la referida STC 173/2011 (FJ nº 7); y al hilo de ella, asimismo, Juan Ocón, op. cit., en particular p. 342.

118 Piénsese en una intervención de las comunicaciones al respecto de un potencial, gravísimo e inminente atentado terrorista, y a fin de evitarlo; no obstante, y de manera análoga a los referidos arts. 579.3, 588. ter.d.3, 588.quinquies.b.4 y 588.sexies.c.3 y 4 LECr, que tal intervención pueda ordenarla el Ministro 
Lo anterior, a su vez, nos abre la posibilidad del control jurisdiccional de la resolución del Magistrado del Supremo en garantía previa de los referidos derechos fundamentales; y ello, en especial, a la vista de la Sentencia del Tribunal Europeo de Derechos Humanos, de 6 septiembre 1978, en el asunto Klass y otros v. Alemania (15473/1989), si bien desde la presunción de conformidad a Derecho de las actuaciones de los servicios de inteligencia, como de los controles estable$\operatorname{cidos}^{119}$. Al respecto, el problema que plantea la Ley Orgánica 2/2002 no es tanto la falta de previsión de un concreto mecanismo de control jurisdiccional ulterior a la resolución previa judicial, sino el carácter secreto de ésta ${ }^{120}$ (art. único.3 in fine, en relación al 13 L 9/1968) ${ }^{121}$, de manera que para el caso de que alguien tenga conocimiento de haber sido objeto de una resolución de este tipo podrá, entendemos, activar los recursos jurisdiccionales correspondientes (art. $241 \mathrm{LO}$ 6/1985), y en última instancia el recurso de amparo (arts. 53.2 y 161.1.b CE, y Tít. III LO 2/1979, de 3 de octubre, del Tribunal Constitucional). Otra cosa es cómo quepa alcanzarse conocimiento válido del contenido de dicha resolución judicial (a lo que se habrá de estar a lo señalado más arriba), y, en especial, que los plazos para interponer el recurso hayan de comenzar a contar desde que se tenga conocimiento fehaciente (en lo posible) de tal resolución (conforme a la conocida tesis de la actio nata $)^{122}$.

Más que una cuestión, está también la apreciación de cómo la urgencia y la necesidad de los anteriores supuestos nos lleva normalmente a actuaciones de inteligencia operativa y táctica; y es que lo normal es que investigaciones de tipo personal que requieran de limitación de derechos y libertades por motivos de seguridad parezcan más propias de operaciones concretas de información, que de

responsable del CNI y su mismo Director, y sin perjuicio, también, de su inmediata comunicación al Magistrado del TS competente a fin de su ulterior control judicial.

119 Sobre esta STEDH: J. BARCELONA LLOP, «Escuchas telefónicas y acción de policía de seguridad (A partir de la Sentencia del TEDH sobre el «caso Malone»)», RAP, n 112, 1987, pp. 68 y ss.; y J.L. GoNZÁLEZ CuSSAC, «Intromisión en la intimidad y servicios de inteligencia... cit., pp. 171-173.

120 También, de manera crítica, vid. A. Aва Catoira, «Rendición de cuentas y servicios de inteligencia», ponencia, en XVII Congreso Asociación de Constitucionalistas de España: Seguridad y libertad en el sistema democrático, Santiago de Compostela, 2019, pp. 25-26/28 en https://www.acoes.es/congreso-xvii/wp-content/ uploads/sites/3/2019/04/Rendici\%C3\%B3n-de-cuentas-y-servicios-de-inteligencia.pdf (05/05/2019).

121 Al respecto de éste (art. 13), y al hilo de la referida Proposición de Ley de reforma de la L 9/1968 122/000021 de 2017 (recuérdese, conforme a la cual se propone un sistema de desclasificación automática de plazos), precisamente la Enmienda $n^{\circ} 7$ (Grupo Parlamentario Confederal de Unidos Podemos-En Comú Podem-En Marea): «De existir indicios de responsabilidad civil, administrativa y penal, sin exclusión alguna, que se conozcan una vez levantada la clasificación de la información, se presumirá que ha operado la interrupción de la prescripción y de la caducidad por todo el tiempo de clasificación de la información, por lo que la prescripción y la caducidad iniciarán a partir de la fecha en que la información se hizo de acceso público».

122 Y según la cual, y conforme al art. 1969 CC, el efectivo conocimiento del perjuicio es requisito para la prescripción de acciones de resarcimiento y responsabilidad por daño; de interés, vid. J.V. MOROTE SARRIón, «La novedosa doctrina del Tribunal Constitucional sobre el computo del plazo de prescripción de la acción de responsabilidad extracontractual de la Administración», RAP, n ${ }^{\circ}$ 147, 1998, en esp. pp. 202, 216 y 217. 
inteligencia estratégica. No en vano el Tribunal Constitucional niega, con carácter general, la legitimidad de investigaciones meramente prospectivas (STC 253/2006, de 11 de septiembre, FJ núm. 2), sin perjuicio de que la finalidad en seguridad nacional sea diversa a la meramente policial al respecto de la prevención ${ }^{123}$, y quepa existir base objetiva para la investigación.

Al hilo de lo anterior, recuérdese que la actividad del CNI puede moverse no sólo en el ámbito propio de la seguridad pública, sino y en particular en la prevención, investigación y persecución de delitos muy graves (p.e., terrorismo); y consecuentemente que se entre en concurrencia con la búsqueda, caución y custodia de pruebas a fin de un ulterior procesamiento penal de los responsables (y como es el caso, claro, del mismo delito de traición por los propios agentes de inteligencia, conforme art. $584 \mathrm{CP})^{124}$. En este sentido se ha de advertir no sólo la prohibición de obtención de pruebas con vulneración de derechos fundamentales y su posterior nulidad judicial (art. 11.1 LO 6/1985), sino la doctrina del «fruto del árbol envenado» en virtud de la cual la información obtenida ilegalmente contamina la ulterior información que se alcance a partir de ella ${ }^{125}$. Y en conexión con ello, también, la obligada destrucción del material relativo a informaciones que, obtenidas mediante autorización judicial, «no guarden relación con el objeto o fines de la misma» (nuevamente, art. único.4 LO 2/2002). Esto, en principio, garantizaría que la limitación de los derechos fundamentales se circunscriba a lo estrictamente necesario para alcanzar los fines específicamente invocados para su autorización judicial; ahora bien, ello plantea problemas respecto a supuestos de «hallazgos casuales» (arts. 579.bis y 588. bis.i LECr) con ocasión de intervenciones en derechos fundamentales (en particular, entradas en domicilios e intervenciones telefónicas) debidamente autorizadas judicialmente en relación a concretas actividades y objetivos del CNI, pues al amparo de ellas

123 Nuevamente STS 1094/2010 (FD nº 2.A).

124 Precisamente, sobre tal supuesto, vid. la condena por delito de traición a un ex agente del CESIDCNI que ofreció información secreta a los servicios de inteligencia rusos a cambio de dinero, en Sentencia de la Audiencia Provincial de Madrid (Sec. 1ª), de 11 de Febrero de 2010 (rec. 36/2009).

125 Al respecto, p.e., la reciente (y con matices) STC 97/2019, de 16 de julio. Además, la no consideración de los miembros del CNI como agentes de la autoridad (art. 5.4 L 11/2002) impide por sí que su labor se dirija directamente a la obtención de pruebas, sin perjuicio de que la información que alcancen pueda ser trasladada a los miembros de los cuerpos y fuerzas de seguridad del Estado, y éstos sí realicen ya la oportuna labor indagatoria. Desde esta perspectiva restrictiva de la actividad del CNI, pero también de la del Magistrado del TS que ha de autorizar las intromisiones de aquél en derechos fundamentales (por cuanto que diversa a la instrucción de proceso penal alguno, mas sin perjuicio de que pueda servir de causa de la misma), vid. otra vez la STS, Sala de lo Penal, 1094/2010 (FD núms. 2.B y D y 4.B). Y sobre la posibilidad de comunicación de aquéllos a otros (policía o fiscalía) al respecto de hechos constitutivos de delitos, cfr.: F.L. PASCUAL SARriá, «El control judicial a la interceptación de las comunicaciones... cit., p. 214; y M.V. López AlfranCA, « ¿Pero quién vigilará a los vigilantes?», Icade. Revista cuatrimestral de las Facultades de Derecho y Ciencias Económicas y Empresariales, $\mathrm{n}^{\circ}$ 92, 2014, pp. 135-136. Por tanto, a fin de garantizar que la investigación policial-criminal de estos últimos y las pruebas que se hallen no devengan «envenenadas», es por lo que resulta todavía más necesario que, desde la misma intervención de los miembros del CNI, queden plenamente garantizados los derechos fundamentales de las personas. 
cabe que se descubran hechos relativos a actos delictivos distintos de los inicialmente investigados por el CNI (debiéndose estar entonces a lo señalado más arriba).

\section{SOBRE LA NECESARIA REFORMA DEL CONTROL JURÍDICO SOBRE LA INTELIGENCIA}

La referida previsión de que el control judicial previo a actuaciones del CNI limitativas de derechos fundamentales corresponda a un concreto Magistrado del Tribunal Supremo nos permite plantear que el conocimiento judicial de aquellas cuestiones relativas a la inteligencia y de carácter secreto, y cualquiera que sea el organismo afecto y el tipo de control (jurisdiccional o previo), se concentre en el Tribunal Supremo ${ }^{126}$; y es que si gran parte de los obstáculos que se plantean en el efectivo control jurídico de la inteligencia es, no ya la reserva a guardar sobre la materia sin más, sino la extrema delicadeza de la misma a fin de garantizar la seguridad (en su sentido más amplio), parece adecuado que el órgano judicial al que la Constitución supone mayores garantías precisamente en asuntos de relevancia política (como son los supuestos de aforamientos constitucionalmente previstos) ${ }^{127}$ sea el competente en tal función (así, el Tribunal Supremo) ${ }^{128}$. No en vano, resulta evidente que para un efectivo control (incluido el político) es absolutamente esencial poder entrar en la materia secreta, sin perjuicio de que ésta se mantenga como tal ante el público en general ${ }^{129}$.

Ello, a su vez, entronca con una oportuna reforma de la regulación de la inteligencia (y del secreto, claro) a tenor de su evolución en este Siglo, por cuanto que más extensa, compleja y especializada dada la ampliación de objetivos que supone hoy la idea de seguridad integral ante la globalización y el progreso tecnológico $^{130}$; una nueva inteligencia que además ha de actuar de manera ordinaria y

126 Aunque sin hacer referencia expresa al TS, $c f r$. C. Ruiz Miguel, «Problemas actuales del derecho de los servicios de inteligencia... cit., pp. 43-44. Y al respecto del referido Anteproyecto de 1996, la propuesta del CGPJ, en Dictamen sobre el mismo de 6 de noviembre de 1996, mediante la previsión de cauce procesal específico ante aquél. Sin embargo, ni la Proposición de Ley de reforma de la L 9/1968 presentada en 2016 por el Grupo Vasco, ni ninguna de las 53 enmiendas presentadas recogen tal opción; lo más, que la declaración de secreto pueda ser impugnada ante el TS (enmiendas 6 y 13).

127 Sin perjuicio de la crisis que vive el aforamiento, vid. M.L. MARTínez Alarcón, «El aforamiento de los cargos públicos. Derecho español y Derecho comparado», TRC, nº 35, 2015, pp. 437 y ss.

128 En tal sentido, si bien al respecto de la impugnación jurisdiccional de la clasificación como secreto llevada a cabo por el Gobierno, vid.: L.M. DíEz-PICAZO, «Secretos oficiales: una propuesta de control», en Sobre secretos oficiales... cit., pp. 37 y ss.; y S.A. SOTO LOSTAL, «Comentarios a la legislación española sobre secretos oficiales a la vista de la Sentencia de la Corte de Apelaciones del Distrito de Columbia (EE. UU.) de 21 de mayo de $2013 \ldots$ cit., en especial p. 408.

129 Sobre tal exigencia del control, con carácter general, J.M. UGARTE, «Control... cit., p. 74.

130 Y del secreto, hemos apuntado arriba, por cuanto que más acorde a la extensión de la actividad de inteligencia según la propia extensión que de la seguridad se da; y así en ajustado equilibrio y respeto al necesario y constante control con el que hacer efectivo el Estado democrático de Derecho. En esta línea, vid. M.P. 
cotidiana en la evaluación y prevención de riesgos constantes, y sobre la que asimismo ha de actuar de forma ordinaria el control judicial, tanto jurisdiccional como previo (art. 117.3 y $4 \mathrm{CE}$ ). Y con ello, dar respuesta adecuada de hasta dónde pueda llegar la inteligencia con relación a las personas y sus derechos, como hasta dónde se pueda llegar judicialmente ante la inteligencia en garantía de aquéllos; son éstas cuestiones básicas y que requieren de respuestas, si no expresamente constitucionales ${ }^{131}$, sí que legales; y no sólo desde el requerimiento constitucional de reserva de ley al respecto de la regulación de los derechos fundamentales y sus legítimas limitaciones (art. 53.1 CE) ${ }^{132}$, sino desde el impulso y el debate público-político que supone la ley para el sistema democrático en su conjunto $^{133}$. Es así que, al margen de las concretas respuestas sustantivas que al respecto se puedan ofrecer (y en particular, desde el Derecho comparado) ${ }^{134}$, insistamos en la necesidad de profundizar en la respuesta misma y a nivel legal a fin de procurar oportuna y adecuada regulación a las nuevas necesidades de control que sobre la inteligencia hoy se advierten (y las deficiencias referidas en las anteriores páginas); y ello, en especial, desde una aproximación básica y conjunta de buena parte de la comunidad de inteligencia ${ }^{135}$.

\section{***}

TITLE: Intelligence services, secret and judicial guarantee of rights

ABSTRACT: This paper analyzes the legal framework of the judicial guarantee of rights concerning the activity of intelligence services. In that sense, we first contextualize intelligence regarding the risk society and the security; then we focus on the intelligence services considering the legal framework of the secret; and finally we study the judicial control of intelligence activity in relation to the guarantee of rights, as well as its deficits and its convenient legal reform purposes.

Cousido GonZÁlez, «Secretos de Estado: cambios reales, políticos y legales en la era de la transparencia», Revista Jurídica de Castilla y León, $\mathrm{n}^{\circ} 33,2014$, pp. 1/23 y ss.

131 Ante el silencio constitucional sobre la inteligencia, pero desde el reconocimiento no sólo de los derechos fundamentales como límites al poder, sino de la misma seguridad; $c f r$. M. REvenGA SÁNCHEZ, «Servicios de inteligencia y derecho a la intimidad», REDC, $\mathrm{n}^{\circ} 61,2001$, p. 62.

132 Nuevamente M. RevenGa SÁNCHEZ, op. cit, pero ahora, pp. 70 y ss. Y específicamente al respecto del tratamiento de datos personales por los servicios de inteligencia, téngase en cuenta la reciente y muy intensa (por su extremado grado garantista del alcance del art. 53.1 CE) STC 74/2019, de 22 de mayo (in integrum).

133 Sobre tal concepción política de la ley, vid. J.F. SÁnchez Barrilao, «Reivindicando la ley», AA.VV. Constitucionalismo crítico: Liber amicorum Carlos de Cabo Martín (I), $2^{\mathrm{a}}$ ed., Tirant lo Blanch, Valencia, 2016, pp. 797 y ss. No en vano y desde el principio democrático, ¿cómo renunciar al debate legislativo que haya de determinar el alcance de la inteligencia y los correlativos controles a ella?; y esto, además, desde la visibilidad que siempre conlleva la regulación legal sobre la materia objeto de la misma, al abrirla democráticamente a la ciudadanía [cfr. A. Ава CATOIRA, «Rendición de cuentas y servicios de inteligencia... cit., pp. $7-7 / 28$.

134 P.e., y otra vez M. Revenga SÁnCHez, mas «El control del Centro Nacional de Inteligencia: una perspectiva comparada», REDC, $\mathrm{n}^{\circ} 116,2019$, pp. 13 y ss.

135 Decimos «de buena parte de la comunidad de inteligencia» a tenor de las características propias de la inteligencia militar al encuadrarse en las Fuerzas Armadas. 
RESUMEN: En este trabajo se analiza el marco jurídico de la garantía judicial de los derechos con relación a la actividad de los servicios de inteligencia. En tal sentido, primero contextualizamos la inteligencia al respecto de la sociedad del riesgo y la seguridad; luego identificamos los servicios de inteligencia y presentamos el régimen jurídico del secreto; y finalmente se estudia el control judicial de la actividad de inteligencia en relación con la garantía de los derechos, así como sus déficits y su conveniente reforma.

KEY WORDS: intelligence services, secret, judicial guarantee of rights.

PALABRAS ClaVE: servicios de inteligencia, secreto, garantía judicial de los derechos.

FECHA RECEPCIÓN: 04.08.2019 FECHA ACEPTACIÓN: 11.09.2019 
